\title{
A Survey of Large Molecules toward the Protoplanetary Nebula CRL 618
}

\author{
Anthony J. Remijan ${ }^{1,2,3}$, Friedrich Wyrowski ${ }^{4}$, Douglas N. Friedel ${ }^{1}$, David S. Meier ${ }^{1}$, and
} Lewis E. Snyder ${ }^{1}$

\begin{abstract}
We present the results of our survey toward the protoplanetary nebula CRL 618 for several large, highly saturated, oxygen bearing organic molecules of biological importance including acetaldehyde $\left(\mathrm{CH}_{3} \mathrm{CHO}\right)$, acetic acid $\left(\mathrm{CH}_{3} \mathrm{COOH}\right)$, dimethyl ether $\left(\mathrm{CH}_{3} \mathrm{OCH}_{3}\right)$, ethanol $\left(\mathrm{CH}_{3} \mathrm{CH}_{2} \mathrm{OH}\right)$, formic acid ( $\left.\mathrm{HCOOH}\right)$ and methyl formate $\left(\mathrm{HCOOCH}_{3}\right)$; large carbon chain molecules including methyl cyanide $\left(\mathrm{CH}_{3} \mathrm{CN}\right)$, methylcyanoacetylene $\left(\mathrm{CH}_{3} \mathrm{C}_{3} \mathrm{~N}\right)$, cyanoacetylene $\left(\mathrm{HC}_{3} \mathrm{~N}\right)$, cyanodiacetylene $\left(\mathrm{HC}_{5} \mathrm{~N}\right)$, and $\mathrm{C}_{6} \mathrm{H}$; and finally smaller molecules including ${ }^{34} \mathrm{SO}$, $\mathrm{SO}_{2}, \mathrm{OC}^{34} \mathrm{~S}$ and $\mathrm{MgNC}$. No biologically important organic molecules were detected. However, we report the first interferometric detections of $\mathrm{CH}_{3} \mathrm{CN}$ and vibrationally excited $\mathrm{HC}_{3} \mathrm{~N}$ and $\mathrm{HC}_{5} \mathrm{~N}$ toward this source. The temperature and distribution of $\mathrm{CH}_{3} \mathrm{CN}$ toward $\mathrm{CRL} 618$ indicates it is formed in the outer envelope surrounding the UC HII region. Furthermore, the P-Cygni line profile and corresponding channel maps of vibrationally excited $\mathrm{HC}_{5} \mathrm{~N}$ supports its distribution in the extended envelope expanding radially from the central star. The detection of vibrationally excited $\mathrm{HC}_{3} \mathrm{~N}$ confirmed the temperature structure and column density of $\mathrm{HC}_{3} \mathrm{~N}$ in the inner envelope found by Wyrowski and colleagues (2003). Finally, our observations clearly indicate that CRL 618 is a good source of large carbon chain species but is a very poor source to detect or produce organic species of biological importance.
\end{abstract}

Subject headings: line:identification - radio lines: stars - stars: AGB and postAGB - stars: individual (CRL 618)

\footnotetext{
${ }^{1}$ Department of Astronomy, University of Mlinois, Urbana, IL 61801

email: friedel@astro.uiuc.edu, meierd@astro.uiuc.edu, snyder@astro.uiuc.edu

${ }^{2}$ Current Address: NASA Goddard Space Flight Center, Earth and Space Data Computing Division, Code 930, Greenbelt, MD 20771

email:aremijan@pop900.gsfc.nasa.gov

${ }^{3}$ National Research Council Resident Research Associate

${ }^{4}$ Max-Planck-Institut für Radioastronomie, Auf dem Hügel 69, D-53121 Bonn, Germany

email: wyrowski@mpifr-bonn.mpg.de
} 


\section{Introduction}

Recently, there have been several surveys for complex molecular species toward massive star-forming regions including W75N, G45.47+0.05, G19.61-0.23 (Remijan et al. 2004a) and Sgr B2(N-LMH) (Hollis et al. 2004; Friedel et al. 2004, Snyder et al. 2002). These massive star-forming regions all have very similar physical conditions. First, they are rich in interstellar dust. Many molecular species, even $\mathrm{H}_{2}$, appear to have their origins on the icy surfaces of dust grains (Hollenbach \& Salpeter 1971). Dust becomes more important as more complex molecules are found in the interstellar medium (ISM). The abundances of large molecules in several regions are much larger than the predicted abundances from ion-molecule gas phase chemistry models (Remijan et al. 2002, Mehringer \& Snyder 1996). Thus, grain surface chemistry has been invoked to account for the large abundance of complex interstellar molecules. Second, the high density of gas and dust limit the amount of UV flux. This is important because UV photons destroy complex molecules (Ehrenfreund et al. 2001). Finally, the hot core regions have high temperatures. It is generally believed that molecules formed via grain surface reactions in a cold collapse phase are then evaporated by thermal heating and thereafter deposited into the gas phase. Typically, if the temperature of dust grains exceed $100 \mathrm{~K}$, the mantles evaporate and species that were frozen on the grain can now escape into the gas phase (Tielens \& Hagen 1982; Hasegawa, Herbst \& Leung 1992). Furthermore, an interesting warm gas phase chemistry may take place after the molecules are evaporated leading to the production of even more complex molecules. Thus, these regions appear to be ideal environments for complex interstellar chemisty to take place. It is logical to assume that similar regions rich in dust, high density, and near a source of high temperature, i.e. $\mathrm{O}$ and $\mathrm{B}$ stars or ultracompact (UC) HII regions, should also contain the necessary chemistry to synthesize large molecular species.

Another astronomical environment that appears to fit the above selection criteria are the extended envelopes of protoplanetary nebulae (PPNe). The PPN phase of stellar evolution occurs at the end of the asymptotic giant branch (AGB) stage, where substantial mass loss is taking place, and before the formation of the white dwarf, after which the temperature becomes high enough to ionize the extended envelope and start the formation of a planetary nebula (PN). This phase of stellar evolution is typically very short, lasting only about ten thousand years. However, during that time a very interesting chemistry may take place in the extended envelope of the post-AGB star. Thus, the extended envelopes of PPNe may be ideal chemical factories to produce large molecules and molecules of biological importance.

CRL 618 (AFGL 618, IRAS 04395+3601) is a carbon-rich, evolved PPN with a thick molecular envelope surrounding a B0 star and an UC HII region (Cernicharo et al. 2001a). However, the complete physical structure of CRL 618 is very complex. CRL 618 has been 
observed in several molecular species at different resolutions and wavelengths. Some of its distinct structures include optical high velocity bipolar outflows (Trammell 2000), a central UC HII region, a low velocity expanding torus of molecular emission and an extended expanding AGB envelope (Sanchez Contreras \& Sahai 2004). In addition to several individual structures, the CSE itself also shows a complex structure and is predicted to exhibit a complex distribution of several different molecular species (Woods et al. 2003). Thus, by observing the molecular envelope in several different molecular species at different excitation temperatures, we can obtain a better understanding of the temperature and density stucture of the CSE. Furthermore, the interactions of the high and low velocity outflows from the embedded evolved star may also contribute significantly to the chemistry in the CSE. For example, within the high velocity bipolar outflow, Ueta, Fong \& Mieinner (2001) discovered distinct near-IR "microstructures". They note that the positions of these "microstructures" occur in shocked regions where the molecular clumps are interfacing with the ambient circumstellar shell. Shocked regions also often trace areas of interesting interstellar chemistry that lead to the formation of complex molecular species. For example, Liu et al. (2002) detected formic acid ( $\mathrm{HCOOH})$ emission from shocked gas toward the Orion Compact Ridge. Also, Hollis et al. (2004), detected emission from propenal $\left(\mathrm{CH}_{2} \mathrm{CHCHO}\right)$ and propanal $\left(\mathrm{CH}_{3} \mathrm{CH}_{2} \mathrm{CHO}\right)$ toward $\mathrm{Sgr} \mathrm{B} 2(\mathrm{~N})$. The formation and widespread distribution of these species are most likely due to shocks in the Sgr B2(N) region that provided the energy necessary for the endothermic reactions to form these species and eventually distribute them into the gas phase. Thus, it appeared that CRL 618 contains the physical conditions necessary to produce complex molecules.

Two recent surveys were performed toward CRL 618 utilizing the Infrared Space Observatory (ISO) and the IRAM $30 \mathrm{~m}$ radio telescope (Cernicharo et al. 2001a, b). These observations made the first detections in the circumstellar medium of the polyacetylenic chains $\mathrm{C}_{4} \mathrm{H}_{2}$ and $\mathrm{C}_{6} \mathrm{H}_{2}$ and made the first detection of circumstellar benzene $\left(\mathrm{C}_{6} \mathrm{H}_{6}\right)$. They also detected the infrared bands of $\mathrm{NH}_{3}$ and $\mathrm{C}_{2} \mathrm{H}_{4}$ and made the first detection in the circumstellar medium of the methylpolyyenes $\mathrm{CH}_{3} \mathrm{C}_{2} \mathrm{H}$ and $\mathrm{CH}_{3} \mathrm{C}_{4} \mathrm{H}$. Obviously, there is a rich chemistry available to form large carbon-chain molecular species, including $\mathrm{HC}_{3} \mathrm{~N}$ and $\mathrm{HC}_{5} \mathrm{~N}$ (Fukasaku et al. 1994). Bujarrabal et al. (1988) also compared the column densities of several molecular species measured toward CRL 618 to what was measured toward other PPN, specifically IRC+10216 and CRL 2688, as well as interstellar molecular clouds, specifically Orion A and TMC-1. What they found was that the abundances of many molecular species, including $\mathrm{HC}_{3} \mathrm{~N}$ and $\mathrm{HC}_{5} \mathrm{~N}$, were more similar to the abundances found in the ISM rather than the other PPNe. Furthermore, it was the first time $\mathrm{HCO}^{+}$was detected in a carbonrich object. Thus, they suggested that CRL 618 was at a particular point in its evolution where the chemistry occuring in the CSE was more likely similar to the chemistry present 
in the ISM than other, more evolved, PPNe. There have been detections of small oxygen bearing molecules toward CRL 618 including $\mathrm{CO}, \mathrm{H}_{2} \mathrm{O}$ and $\mathrm{H}_{2} \mathrm{CO}$ (Cernicharo et al. 1989). However, there has not been a detection of any large oxygen bearing organic molecule toward this source even though CRL 618 appears to be the ideal CSE environment to search for oxygen bearing organic molecules as well as other large molecular species.

Thus, to investigate whether the chemistry present toward CRL 618 can produce large oxygen bearing organic molecules, we used the Berkeley-Illinois-Maryland Association (BIMA) Array $^{5}$ to carry out a large molecule survey toward this region. Included in the survey were transitions of formic acid $(\mathrm{HCOOH})$, acetic acid $\left(\mathrm{CH}_{3} \mathrm{COOH}\right)$, methyl formate $\left(\mathrm{HCOOCH}_{3}\right)$, acetaldehyde $\left(\mathrm{CH}_{3} \mathrm{CHO}\right)$ as well as methyl cyanide $\left(\mathrm{CH}_{3} \mathrm{CN}\right)$, cyanoacetylene $\left(\mathrm{HC}_{3} \mathrm{~N}\right)$ and cyanodiacetylene $\left(\mathrm{HC}_{5} \mathrm{~N}\right)$. The observations of these large molecules not only helped constrain the chemistry present toward CRL 618 but also the temperature and column density of large molecular species in the surrounding circumstellar environment.

\section{Observations}

The large molecule survey took place from 2002 October to 2003 February utilizing the $\mathrm{B}$ and $\mathrm{C}$ configurations of the BIMA Array. The minimum baseline for these observations was $\sim 8 \mathrm{~m}$, and the maximum baseline was $\sim 150 \mathrm{~m}$, providing angular resolutions of $\sim 2^{\prime \prime}$ $13^{\prime \prime}$. Table 1 lists the observational parameters of our survey toward CRL 618. Column (1) lists the observation date. Column (2) lists the source used to calibrate the antenna based gains and column (3) lists the flux density calibrator. The absolute amplitude calibration of these sources is accurate to within $\sim 20 \%$. We find a flux density of the source of 1.86 Jy at the continuum emission peak of our observations at $108 \mathrm{GHz}$ which is very similar to the flux density measured by Wyrowski et al. (2003) of $1.8 \mathrm{Jy}$ measured with the IRAM $30 \mathrm{~m}$ radio telescope at $109.2 \mathrm{GHz}$. Column (4) lists the observing frequency of the upper sideband and column (5) lists the array configuration of the observation. Finally, column (6) lists the corresponding beamsize. In order to obtain the best signal-to-noise at each observing frequency, all the data from the source with multiple tracks and in multiple arrays were inverted in $u$-v space. The resulting synthesized beamsize $\left(5^{\prime \prime} .8 \times 5^{\prime \prime} .1\right.$ near $\left.108 \mathrm{GHz}\right)$ was determined by the region of densest $u$-v coverage and the $1 \sigma \mathrm{rms}$ noise level of the final maps was determined by selecting a region free from line and continuum emission. The

\footnotetext{
${ }^{5}$ Operated by the University of California, Berkeley, the University of Illinois, and the University of Maryland with support from the National Science Foundation.
} 
passbands were calibrated automatically during data acquisition ${ }^{6}$ and this method has been quite satisfactory and has not generated spurious features.

Table 2 lists the molecular parameters of the 44 transitions of the 15 molecular species searched for in our survey. Column (1) lists the species; Column (2) lists the transition. Column (3) lists the calculated rest frequency and its $2 \sigma$ standard deviation. Column (4) lists the product of the line strength and the square of the relevant dipole moment; and column (5) lists the upper state energy level of each transition. Finally, the estimated rotational partition functions for each molecular species are given in column (6). The spectral windows containing these transitions had a bandwidth of $50 \mathrm{MHz}$ and were divided into 128 channels for a spectral resolution of $0.39 \mathrm{MHz}$ per channel. All data were combined, imaged, and self-calibrated using the MIRIAD software package (Sault, Teuben \& Wright 1995). The $1 \sigma \mathrm{rms}$ noise level of the final maps was used to set upper limits to the column densities of the undetected molecular species searched for in our survey (§4.4).

\section{Results}

Figure 1 shows the four transitions of vibrationally excited $\mathrm{HC}_{5} \mathrm{~N}$ located in the passbands of our survey. The $\mathrm{HC}_{5} \mathrm{~N}$ transitions and corresponding rest frequencies were taken from a new survey by Yamada et al. (2004) and from the Cologne Database for Molecular Spectroscopy (Müller et al. 2001). In Figure 1a) we show the first interferometric detection of vibrationally excited $\left(v_{11}=1\right) \mathrm{HC}_{5} \mathrm{~N}$ toward CRL 618. The spectral line labels located in the upper left of each panel correspond to the rest frequency of each $\mathrm{HC}_{5} \mathrm{~N}$ transition for a $v_{L S R}$ of $-27.5 \mathrm{~km} \mathrm{~s}^{-1}$ (dashed line). The $1 \sigma$ noise level is seen at the left of each panel. The classic P-Cygni line profile indicates that $\mathrm{HC}_{5} \mathrm{~N}$ is present in an expanding envelope of material. Also included in Figure 1a) are the spectral line labels of $\mathrm{C}_{6} \mathrm{H}$ and ${ }^{34} \mathrm{SO}$. These features will be discussed in more detail ( $\$ \$ 4.4 \& 4.5)$. Figures 1 b)-1d) show the spectra of higher vibrational transitions $\left(v_{11}=3\right.$ and 4$)$ that were not detected beyond our $1 \sigma$ detection limit. From these non-detections, we were able to set a upper limit on the temperature of this species in this region. Finally, in Figure 1d), we label the location of MgNC. The non-detection of this feature will also be discussed in more detail ( $\$ 4.4)$.

Figure 2 shows the spectra of the $\mathrm{CH}_{3} \mathrm{CN}$ and vibrationally excited $\mathrm{HC}_{3} \mathrm{~N}$ detected in our survey. Figure 2a) shows the first detection of the $J=6-5$ rotational transitions of $\mathrm{CH}_{3} \mathrm{CN}$. All the $\mathrm{CH}_{3} \mathrm{CN}$ transitions are seen in emission. Between the $K=2$ and $K=3$ lines of $\mathrm{CH}_{3} \mathrm{CN}$ lies the $J=12-11,(0,1,0,3)^{1+}$ vibrational transition of $\mathrm{HC}_{3} \mathrm{~N}$ seen in

\footnotetext{
${ }^{6} \mathrm{~A}$ technical description of this can be found at http://astron.berkeley.edu/ plambeck/technical.html
} 
absorption. The measured $v_{L S R}$ of the absorption trough is $-27.5 \mathrm{~km} \mathrm{~s}^{-1}$ which is consistent with previous detections of vibrationally excited $\mathrm{HC}_{3} \mathrm{~N}$ (Wyrowski et al. 2003). Finally, Figure 2b) shows the spectrum of 3 vibrationally excited transitions of $\mathrm{HC}_{3} \mathrm{~N}$. Once again, each of these transitions lie at a $v_{L S R}$ of $-27.5 \mathrm{~km} \mathrm{~s}^{-1}$. The spectral line labels located in the upper left of each panel correspond to the rest frequency of the $\mathrm{HC}_{3} \mathrm{~N} J=12-11$, $(0,1,0,3)^{1+}$, and the $\mathrm{HC}_{3} \mathrm{~N} J=12-11,(0,0,0,4)^{0}$ transitions $^{7}$, respectively. Table 3 lists the molecular species that were detected toward CRL 618 at or near the systemic velocity ( -27.5 $\mathrm{km} \mathrm{s}^{-1}$ ). Least square Gaussian fits were made for each spectral line in order to obtain the radial velocities and integrated line intensities for the detected transitions. In Table 3 , column (1) lists the calculated rest frequencies of the identified species. Columns (2) and (3) list the molecular species and associated transitions, respectively. Column (4) lists the $v_{L S R}$ corresponding to the emission or absorption components of each spectral feature. Finally, column (5) lists the fitted integrated line intensity of each detected transition and the associated $1 \sigma$ uncertainty.

Figure 3 shows the $\mathrm{HC}_{5} \mathrm{~N}$ velocity-channel maps toward $\mathrm{CRL}$ 618. The spectral line channel maps displayed are a combination of the $\mathrm{B}$ and $\mathrm{C}$ array data. The $v_{L S R}$ intervals are indicated in $\mathrm{km} \mathrm{s}^{-1}$ units at the top right of each panel. The synthesized beam of $5 . " 8 \times 5 . " 1$ is shown at the bottom left of each velocity-channel map. The lowest contour plotted is $0.08 \mathrm{Jy} \mathrm{beam}^{-1}$ which corresponds to $2 \sigma$. The absorption peaks near a $v_{L S R}$ of $-34 \mathrm{~km}$ $\mathrm{s}^{-1}$ and the emission peaks near $-24 \mathrm{~km} \mathrm{~s}^{-1}$. Both the absorption and emission peaks are coincident with the high resolution B-array $3 \mathrm{~mm}$ continuum shown in the last panel of the figure (synthesized beam of $3 . " 0 \times 1 . " 9$ ). Thus, it is apparent from both the P-Cygni profile and velocity-channel maps that $\mathrm{HC}_{5} \mathrm{~N}$ is contained in an expanding envelope and not in the bipolar outflows.

Figure 4 shows the $\mathrm{HC}_{3} \mathrm{~N}$ velocity-channel maps toward $\mathrm{CRL}$ 618. As in Figure 3, the data displayed are a combination of the $\mathrm{B}$ and $\mathrm{C}$ array data and the $v_{L S R}$ intervals are indicated at the top right of each panel. In this case, we see no emission features of $\mathrm{HC}_{3} \mathrm{~N}$. This is not unexpected because all of the high energy, high vibrational state transitions (i.e. $v_{5}=1 ; v_{7}=3$ ) detected by Wyrowski et al. (2003) were seen primarily in absorption. The transitions detected in our survey were a higher vibrational state $\left(v_{7}=3 \& 4\right)$ than the transitions of the Wyrowski et al. (2003) survey but the upper state energy levels were comparable to some of the higher energy transitions detected in their survey. In contrast, the ground state and first vibrational states in the Wyrowski et al. (2003) survey were seen primarily in emission. Once again, we see the absorption is coincident with the $3 \mathrm{~mm}$

\footnotetext{
${ }^{7}$ The notation given for the vibrational excited transitions of $\mathrm{HC}_{3} \mathrm{~N}$ is defined as $\left(v_{4}, v_{5}, v_{6}, v_{7}\right)^{l}$, where $v$ is the vibrational quantum number and $l$ is the $l$-type doubling quantum number (Thorwirth et al. 2003).
} 
continuum and presumably all the vibrationally excited $\mathrm{HC}_{3} \mathrm{~N}$ is contained in the CSE.

Finally, we note that we did not detect any emission or absorption features from any of the other molecular species listed in Table 2 beyond our $1 \sigma$ detection limit. These include all the oxygen bearing organic molecules as well as $\mathrm{CH}_{3} \mathrm{C}_{3} \mathrm{~N}, \mathrm{C}_{6} \mathrm{H}$, and all of the smaller molecular species. However, it does appear that we are starting to detect the $N=9-8$ transition of MgNC in Figure 1d). Higher signal-to-noise interferometric observations are necessary to confirm this detection. Based on the $1 \sigma$ detection limit, we were able to place upper limits on the species that were not detected. All column densities and upper limits are listed in Table 4 (\$4.4). In $\$ 4.5$ we discuss these upper limits along with the predicted fractional abundances based on the gas phase formation models of Woods et al. (2003) and of the UMIST database (Le Teuff et al. 1999).

\section{Analysis and Discussion}

One of the most important physical parameters to determine in either an interstellar or circumstellar environment is the total beam averaged column density of a molecular species. There are three primary procedures used in calculating the total beam averaged column density of a particular molecular species, each of which are described in detail in Remijan et al. (2004b). For our purposes, we will utilize the rotational temperature diagram method (RTDM) for the $\mathrm{CH}_{3} \mathrm{CN}$ and $\mathrm{HC}_{5} \mathrm{~N}$ emission, and to assume local thermodynamic equilibrium (LTE) for all other molecular species. From Remijan et al. (2003), the total beam averaged column density is given as:

$$
N_{T}=2.04 \times C_{\tau} \frac{\int \Delta I d v}{\theta_{a} \theta_{b}}\left[\frac{I\left(T_{e}\right)}{I\left(T_{e}\right)-I_{b}}\right] \frac{Q_{r v} e^{\left(E_{u} / T_{e}\right)}}{\nu^{3}<S_{i j} \mu^{2}>} \times 10^{20} \mathrm{~cm}^{-2}=C_{\tau} N_{T}^{\text {thin }} \mathrm{cm}^{-2}
$$

In equation (1), $N_{T}$ is the total column density for any optical depth and $N_{T}^{\text {thin }}$ is the total column density for the optically thin case. $C_{\tau}$ is the optical depth correction factor from Goldsmith \& Langer (1999). $\int \Delta I d v\left(\mathrm{Jy}_{\text {beam }}^{-1} \mathrm{~km} \mathrm{~s}^{-1}\right)$ is the integrated line intensity given in Table $3 ; \theta_{a}$ and $\theta_{b}$ are the FWHM beam sizes (arcsec), $I\left(T_{e}\right)$ is the specific intensity of the source at $T_{e}\left(\mathrm{Jy} \mathrm{beam}^{-1}\right)$, and $I_{b}$ is the specific intensity of the total background continuum contribution ( $\mathrm{Jy}_{\text {beam }}{ }^{-1}$ ). $Q_{r v}$ is a combination of the rotational and vibrational partition functions. The vibrational part of the partition function needed to be applied to both the $\mathrm{HC}_{5} \mathrm{~N}$ (Müller et al. 2001) the $\mathrm{HC}_{3} \mathrm{~N}$ (Wyrowski et al. 2003) column density calculations. $E_{u}$ is the upper state energy level $(\mathrm{K}), T_{e}$ is the rotational temperature $(\mathrm{K})$, $\nu$ is the rest frequency $(\mathrm{GHz})$, and $S_{i j} \mu^{2}$ is the product of the total torsional-rotational line 
strength and the square of the electric dipole moment (Debye ${ }^{2}$ ).

\subsection{Methyl Cyanide $\left(\mathrm{CH}_{3} \mathrm{CN}\right)$}

Methyl cyanide $\left(\mathrm{CH}_{3} \mathrm{CN}\right)$ has been used as an excellent tracer of the physical and chemical conditions toward high mass star forming regions of the interstellar medium (ISM) (Remijan et al. 2004b; Sutton et al. 1986). $\mathrm{CH}_{3} \mathrm{CN}$ is a symmetric top molecule which has properties that makes it an ideal probe of kinetic temperature and column density. In a symmetric top, the rotational levels are labeled by $J$, the total angular momentum quantum number, and $K$, the quantum number for the projection of angular momentum along the symmetry axis (Cummins et al. 1983). By selection rules, radiative transitions do not change the value of $K$. However, collisional transitions are permitted across $K$ ladders. Therefore, the population of one $K$ ladder relative to another is largely determined by collisions and hence, is closely related to the kinetic temperature and density (Solomon et al. 1971). The first reported detection of $\mathrm{CH}_{3} \mathrm{CN}$ toward $\mathrm{CRL} 618$ was by Bujarrabal et al. (1988) using the IRAM 30m radio telescope. Also using the IRAM 30m, Guelin \& Cernicharo (1991) used several millimeter transitions of $\mathrm{CH}_{3} \mathrm{CN}$ to examine the physical conditions toward $\mathrm{IRC}+10216$. From their observations, they found a rotation temperature of $\mathrm{T}_{\text {rot }}=16 \mathrm{~K}$ and a column density of $6 \times 10^{12} \mathrm{~cm}^{-2}$ toward IRC+10216 (Guelin \& Cernicharo 1991). Figure 5 shows the results of the RTDM toward CRL 618 using the $J=6-5$ transitions. Because the $K=0 \& 1$ transitions are severely blended, we could not resolve the lines into two separate Gaussians, thus we included the pair as one point on the rotational temperature diagram by separating the intensity by their appropriate statistical weights and then averaging. Using the procedures outlined in Remijan et al. (2004b) we found a best fit rotational temperature of $88(44) \mathrm{K}$ and a total beam averaged column density of $3.2(3) \times 10^{14} \mathrm{~cm}^{-2}$. Assuming an $\mathrm{H}_{2}$ column density of $\sim 1.3 \times 10^{23} \mathrm{~cm}^{-2}$ (Woods et al. 2003), we find a fractional abundance of $X_{\mathrm{CH}_{3} \mathrm{CN}}=2.4(3) \times 10^{-9}$. This value is very close to the predicted peak value of $\sim 10^{-8}$ from the Woods et al. (2003) model at a radial distance of $\sim 9.1 \times 10^{15} \mathrm{~cm}$ from the exciting star. Thus, it is clear from our observations that $\mathrm{CH}_{3} \mathrm{CN}$ appears to reside in the outer regions of the expanding envelope. Furthermore, transitions of vibrationally excited $\mathrm{CH}_{3} \mathrm{CN} v_{8}=1$ were below our $1 \sigma$ detection limit, which again may imply that $\mathrm{CH}_{3} \mathrm{CN}$ exists in the outer envelope. 


\subsection{Cyanoacetylene $\left(\mathrm{HC}_{3} \mathrm{~N}\right)$}

Cyanoacetylene $\left(\mathrm{HC}_{3} \mathrm{~N}\right)$ is a carbon chain molecule that has been extensively studied toward CRL 618 in both the ground and excited vibrational states (see e.g. Pardo et al. 2004; Wyrowski et al. 2003 and references therein). So, from our data, we were able to check the previously measured physical conditions and help further constrain the physical and chemical models of CRL 618. In Figure 2), we show the detections of 4 vibrationally excited transitions of $\mathrm{HC}_{3} \mathrm{~N}$. Also shown in these spectra are the best fit modelled spectra to the data given as a solid line. In order to calculate the best fit spectra, we used the spectral line parameters given in Table 2 and used a FWHM line width of $\Delta v=5 \mathrm{~km} \mathrm{~s}^{-1}$ based on the fits in Table 3. Models were constructed using the temperature and upper state column density as input parameters. We varied the temperature between 400 and $600 \mathrm{~K}$ and the upper state column density between $10^{16}$ and $10^{18} \mathrm{~cm}^{-2}$. We then calculated the $\chi^{2}$ between the model and the data and found the minimum $\chi^{2}$. The best fit models (solid lines) are shown in Figure 2) for a temperature of $580(150) \mathrm{K}$ and a total $\mathrm{HC}_{3} \mathrm{~N}$ beam averaged column density of $4.7(6) \times 10^{17} \mathrm{~cm}^{-2}$. The errors given for the temperature and total column density are 3 $\sigma$ errors based on the fit, thus giving a $99 \%$ confidence interval. The only line that does not seem to fit the model very well is the $\mathrm{J}=12-11(0,0,0,4)^{4}$ transition at $110.555 \mathrm{GHz}$ (Table 2). This line may be blended with the $15_{4,2}-14_{5,2}$ transition of $\mathrm{c}-\mathrm{C}_{3} \mathrm{H}_{2}$ at $110.558(9) \mathrm{GHz}$ (Pickett et al. 1998) or possibly from another unknown circumstellar species. The values of $T_{\text {rot }}$ and $\mathrm{N}_{T}$ are very similar to the values determined by Wyrowski et al. (2003) of $\mathrm{T}=520(80) \mathrm{K}$ and a total $\mathrm{HC}_{3} \mathrm{~N}$ column density between $(3-6) \times 10^{17} \mathrm{~cm}^{-2}$. In order to find the total $\mathrm{HC}_{3} \mathrm{~N}$ column density, we needed to include the vibrational part of the partition function. Using Figure 9) in Wyrowski et al. (2003), for a temperature of $580 \mathrm{~K}$, we find $Q_{r v}=1.8 \times 10^{5}$. Also, in equation (1) we needed to account for the optical depth and the intensity of the background continuum. For the $\mathrm{HC}_{3} \mathrm{~N}$ lines, we find $\tau=\ln \left(\mathrm{T}_{c} / \mathrm{T}_{c}-\mathrm{T}_{L}\right)=0.25$ which gives an optical depth correction factor of $\mathrm{C}_{\tau}=1.13$ and using the continuum temperature and the excitation temperature of $580 \mathrm{~K}$, the column density correction due to $I\left(T_{e x}\right) /\left(I\left(T_{e x}\right)-I_{b}\right)$ is $\sim 1.06$ which gives a total correction of $\sim 1.20$ for a temperature of $580 \mathrm{~K}$. Assuming an $\mathrm{H}_{2}$ column density of $\sim 1.3 \times 10^{23} \mathrm{~cm}^{-2}$ (Woods et al. 2003), we find a fractional abundance of $X_{\mathrm{HC}_{3} \mathrm{H}}=3.6(5) \times 10^{-6}$, which match the models of Woods et al. (2003). The average value of the $\mathrm{HC}_{3} \mathrm{~N}$ fractional abundance in the envelope predicted by the model is $\sim 10^{-6}$ and the model predicts a peak value of $1.6 \times 10^{-6}$ at a radial distance of $\sim 10^{16} \mathrm{~cm}$ from the central star. Thus, it appears that the models are predicting the relative abundances of this species very well toward CRL 618. 


\subsection{Cyanodiacetylene $\left(\mathrm{HC}_{5} \mathrm{~N}\right)$}

The first reported detection of $\mathrm{HC}_{5} \mathrm{~N}$ in a PPN was by Winnewisser \& Walmsley (1978) toward IRC+10216. They observed the $J=9-8$ rotational transition near $24 \mathrm{GHz}$. From their observations, they found the $\mathrm{HC}_{5} \mathrm{~N}$ emission to be quite extended over their $40^{\prime \prime}$ beam and measured a $\mathrm{HC}_{5} \mathrm{~N}$ column density of $4 \times 10^{14} \mathrm{~cm}^{-2}$. However, they did not detect any emission from the $v_{11}=1$ vibrational mode. These observations were later followed up by Jennings \& Fox (1982) who determined an $\mathrm{HC}_{5} \mathrm{~N}$ rotational temperature of $13_{-4}^{+12} \mathrm{~K}$, which was in agreement with the determined $\mathrm{HC}_{3} \mathrm{~N}$ rotational temperature of $12 \mathrm{~K}$ measured at the time. The first detection of $\mathrm{HC}_{5} \mathrm{~N}$ in CRL 618 was by Bujarrabal et al. (1988). In this case, they assumed the $\mathrm{HC}_{5} \mathrm{~N}$ emission to be much smaller than their beam of $\sim 15^{\prime \prime}$. From that, they found an $\mathrm{HC}_{5} \mathrm{~N}$ rotational temperature of $\sim 81 \mathrm{~K}$. Since then, several other transitions of $\mathrm{HC}_{5} \mathrm{~N}$ have been observed toward other PPNe (see e.g. Fukusaka et al. 1994). The first detection of vibrationally excited transitions of $\mathrm{HC}_{5} \mathrm{~N}$ reported in $\mathrm{CRL} 618$ was by Thorwirth (2001). Later observations followed by Cernicharo et al. (2001a) and Wyrowski et al. (2003). However, ours are the first data of vibrationally excited $\mathrm{HC}_{5} \mathrm{~N}$ taken with an interferometer and the first maps of vibrationally excited $\mathrm{HC}_{5} \mathrm{~N}$ toward $\mathrm{CRL} 618$. In Figure 1, we showed the first interferometric detection of the $J=40-39, v_{11}=1$ transition of $\mathrm{HC}_{5} \mathrm{~N}$. No higher vibrational states $\left(v_{11}=3\right.$ or 4$)$ were detected (Figures $1 \mathrm{~b}-\mathrm{d}$ )). However, from the $1 \sigma$ noise levels, we were able to plot the upper limits on a rotational temperature diagram of $\mathrm{HC}_{5} \mathrm{~N}$. Plotting these data on a rotational temperature diagram, we were able to determine an upper limit to the $\mathrm{HC}_{5} \mathrm{~N}$ rotational temperature of $T_{\text {rot }}=114 \mathrm{~K}$. Using the measured vibrationally excited partition function from Müller et al. (2001) for $\mathrm{HC}_{5} \mathrm{~N}$, we were able to calculate the total rotational-vibrational $\mathrm{HC}_{5} \mathrm{~N}$ partition function for $114 \mathrm{~K}$. We find $\mathrm{Q}_{r v}=\sim 950$. From the rotational temperature diagram, we find a total beam averaged column density of $\mathrm{HC}_{5} \mathrm{~N}$ of $\sim 10^{15} \mathrm{~cm}^{-2}$ and a fractional abundance of $X_{\mathrm{HC}_{5} \mathrm{~N}}=7.6 \times 10^{-9}$. This column density is about an order of magitude lower than the predicted value of $1.7 \times 10^{16} \mathrm{~cm}^{-2}$ from the Woods et al. (2003) model. However, the column density is in the range of measured values toward this source from previous observations (Fukasaku et al. 1994, Cernicharo et al. 2001a).

Also, looking at the velocity-channel maps in Figure 2, we see the $\mathrm{HC}_{5} \mathrm{~N}$ emission is coincident with the $3 \mathrm{~mm}$ continuum and that no $\mathrm{HC}_{5} \mathrm{~N}$ emission is seen in the bipolar outflow above our $3 \sigma$ detection limit cutoff. The classic P-Cygni line profile indicates a spherically symmetric expansion with an expansion velocity of $\sim 5-7 \mathrm{~km} \mathrm{~s}^{-1}$. The slow expansion velocity would occur at the outer edges of the envelope as the expanding material begins to interact with the remnant AGB wind. Also, the expansion velocity of $\mathrm{HC}_{5} \mathrm{~N}$ is close to the measured expansion velocity of $\mathrm{HC}_{3} \mathrm{~N}\left(\sim 10 \mathrm{~km} \mathrm{~s}^{-1}\right)$ found by Pardo et al. (2004)

and it matches the expansion velocity used by Woods et al. (2003) in their formation models. Thus from the spectral line profile and mapping data, it appears that $\mathrm{HC}_{5} \mathrm{~N}$ is found in the 
extended circumstellar envelope.

To summarize, all the detected species are found in the extended envelope. In the case of $\mathrm{CH}_{3} \mathrm{CN}$, the observed transitions are low in upper state energy and optically thin. Thus, we are probing the gas in the very extended envelope and should only see emission features. On the other hand, the $\mathrm{HC}_{3} \mathrm{~N}$ transitions have high upper state energies. The gas sampled in this case must lie deeper in the envelope where the column density is high which leads to a high opacity and the lines are seen primarily in absorption. Transitions of $\mathrm{HC}_{3} \mathrm{~N}$ at a lower energy state with respect to the transitions we observed are seen by other authors in emission and as P-Cygni profiles. This implies these authors are sampling the outer envelope where the gas is at a lower temperature but the column density is high enough where there are competing effects of emission and absorption (see e.g. Pardo et al. 2004). Finally, for $\mathrm{HC}_{5} \mathrm{~N}$, the temperature implies the gas resides in the outer envelope, intermediate between the vibrational $\mathrm{HC}_{3} \mathrm{~N}$ and lower energy $\mathrm{CH}_{3} \mathrm{CN}$ transitions, and the column density is high enough where, once again, there are competing effects of emission and absorption. The hypothesis based on the formation models of each species (Woods et al. 2003 ) is that $\mathrm{CH}_{3} \mathrm{CN}, \mathrm{HC}_{3} \mathrm{~N}$ and $\mathrm{HC}_{5} \mathrm{~N}$ are probably contained throughout the CSE of CRL 618. In order to fully investigate that assumption, observations of transitions that sample a wide range of upper state energy levels of each species are necessary.

\subsection{Column Density Upper Limits of the Remaining Molecular Species.}

Of the remaining species listed in Table 1), we only detected emission from ${ }^{34} \mathrm{SO}$ (Figure 1a). Because this line was near the edge of the spectral window, we were not able to make a Gaussian fit or a calculation of the total ${ }^{34} \mathrm{SO}$ beam averaged column density. However, this is the first detection of this isotopic species of SO in a PPN. Further observations of ${ }^{34} \mathrm{SO}$ and ${ }^{32} \mathrm{SO}$ will be needed in order to determine the isotopic ratio and compare the column densities with other detected $\mathrm{O}$ bearing species including $\mathrm{CO}$ and $\mathrm{H}_{2} \mathrm{O}$ toward $\mathrm{CRL} 618$ (Herpin \& Cernicharo 2000).

We also note that we did not reliably detect any emission from the $N=9-8$ transition of magnesium isocyanide ( $\mathrm{MgNC}$ ). This species was recently detected using the Arizona Radio Observatory (ASO) $12 \mathrm{~m}$ and the IRAM $30 \mathrm{~m}$ telescopes via five rotational transitions at $95.4,131.2,143.2,151.1$, and $167.0 \mathrm{GHz}$. The column density of MgNC from that survey was found from a rotational temperature diagram to be $2.4 \times 10^{12} \mathrm{~cm}^{-2}$ with a $T_{\text {rot }}=21 \mathrm{~K}$ (Highberger \& Zuirys 2003). They note the derived rotational temperature is consistent with the kinetic temperature of $\sim 50 \mathrm{~K}$ (Herpin et al. 2002). Using this column density, we can predict the expected line intensity for our observations. Using a rotational temperature 
of $21 \mathrm{~K}$, we predict an intensity of $\sim 0.035 \mathrm{Jy} \mathrm{beam}^{-1}$ for our BIMA observations. If the temperature is closer to the $\mathrm{CH}_{3} \mathrm{CN}$ temperature of $88 \mathrm{~K}$, the predicted intensity drops to $\sim 0.022 \mathrm{Jy}$ beam $^{-1}$. The average rms noise of the combined $\mathrm{B}$ and $\mathrm{C}$ array dataset containing the $\mathrm{MgNC}$ transition is $\sim 0.04 \mathrm{Jy}_{\text {beam }}{ }^{-1}$. Thus, even with the highest predicted line intensity, we would have only detected this transition at the $\sim 1 \sigma$ level. In Figure 1d), we labeled the position of the $\mathrm{MgNC}$ transition and it appears the line is beginning to be resolved out of the noise. However, higher signal-to-noise interferometric observations are necessary to claim this as a detection.

No other molecular species was detected toward CRL 618 beyond the $1 \sigma$ detection limit. However, we were able to set upper limits to the column densities of those species based on the $1 \sigma \mathrm{rms}$ noise level $\left(\sim 0.04 \mathrm{Jy} \mathrm{beam}^{-1}\right)$ and an average line width of $\sim 5 \mathrm{~km}$ $\mathrm{s}^{-1}$ and assuming a temperature of $88 \mathrm{~K}$ found from the $\mathrm{CH}_{3} \mathrm{CN}$ data. Table 4 summarizes the column densities of all molecular species including upper limits. Column (1) lists the molecular species observed toward CRL 618. Column (2) lists the frequency of the transition used to calculate the upper limit to the total column density ( $\mathrm{MHz}$ ). Using equation (1), an average beam of $25 \operatorname{arcsec}^{2}$, and the spectroscopic parameters and partition functions in Table 2, we were able to calculate the total beam averaged column densities of each molecular species. Column (3) lists the total beam averaged column density $\left(\mathrm{cm}^{-2}\right)$. Finally, Column (4) lists the fractional abundance of each molecular species with respect to $\mathrm{H}_{2}$ assuming an $\mathrm{H}_{2}$ column density of $1.3 \times 10^{23} \mathrm{~cm}^{-2}$.

\subsection{Formation and Detection of Oxygen Bearing Organic Biomolecules in Protoplanetary Nebulae}

Our detections of $\mathrm{CH}_{3} \mathrm{CN}, \mathrm{HC}_{3} \mathrm{~N}$ and $\mathrm{HC}_{5} \mathrm{~N}$ strongly suggest that the chemistry present toward CRL 618 is conducive to producing large carbon-chain molecules and the formation models that predict the abundance of these species also match the measured abundances very well. The only large carbon-chain molecule that was predicted to be present in a large abundance toward CRL 618 but was not detected was $\mathrm{C}_{6} \mathrm{H}$. Woods et al. (2003) predict a total column density of $2.5 \times 10^{15} \mathrm{~cm}^{-2}$ and our measured upper limit was two orders of magnitude lower at $2.5 \times 10^{13} \mathrm{~cm}^{-2}$. Also, there is no formation model that takes into account methylcyanoacetylene $\left(\mathrm{CH}_{3} \mathrm{C}_{3} \mathrm{~N}\right)$ and our measured upper limit is $3.3 \times 10^{13} \mathrm{~cm}^{-2}$. However, the models of Woods et al. (2003) predict the column densities of $\mathrm{CH}_{3} \mathrm{C}_{4} \mathrm{H}$ and $\mathrm{C}_{6} \mathrm{H}_{5} \mathrm{CN}$ to be $1.5 \times 10^{15} \mathrm{~cm}^{-2}$, which are presumed to be more complex species than either $\mathrm{C}_{6} \mathrm{H}$ or $\mathrm{CH}_{3} \mathrm{C}_{3} \mathrm{~N}$. Thus, if the formation models are correct, we should have easily detected $\mathrm{C}_{6} \mathrm{H}$. If the predicted column density of $\mathrm{CH}_{3} \mathrm{C}_{3} \mathrm{~N}$ is similar to either $\mathrm{CH}_{3} \mathrm{C}_{4} \mathrm{H}$ or $\mathrm{C}_{6} \mathrm{H}_{5} \mathrm{CN}$, we should 
have also easily detected $\mathrm{CH}_{3} \mathrm{C}_{3} \mathrm{~N}$. The fact that neither species was detected beyond our $1 \sigma$ detection limit implies the calculated upper limit of $\sim 10^{13} \mathrm{~cm}^{-2}$ for both $\mathrm{C}_{6} \mathrm{H}$ and $\mathrm{CH}_{3} \mathrm{C}_{3} \mathrm{~N}$ must be taken into account in future formation models.

The non-detections of very favorable transitions of oxygen bearing organic molecules such as $\mathrm{HCOOH}, \mathrm{HCOOCH}_{3}$ and $\mathrm{CH}_{3} \mathrm{COOH}$, however, imply that the chemistry of PPNe may not be conducive to form large organic molecules of biological interest (biomolecules). In fact, the only biomolecules that have been detected toward a PPN are formaldehyde $\left(\mathrm{H}_{2} \mathrm{CO}\right)$ (Cernicharo et al. 1989) toward $\mathrm{CRL} 618$ and a tentative but unverified detection of methanol $\left(\mathrm{CH}_{3} \mathrm{OH}\right)$ toward IRC+10216 (Latter \& Charnley 1996). There are numerous chemical models that have been utilized to try and explain the formation and measured abundances of oxygen bearing organic molecules in the ISM and CSE. These models include many different types of energetics including shocks and thermal heating to drive the predicted chemistry. For our purposes, we will only include a brief overview of some models and how they may apply to CSEs.

In the case of forming $\mathrm{CH}_{3} \mathrm{OH}$ and $\mathrm{H}_{2} \mathrm{CO}$ in a $\mathrm{CSE}$, shock chemistry is invoked to explain the formation of $\mathrm{H}_{2} \mathrm{CO}$ and $\mathrm{CH}_{3} \mathrm{OH}$. It is believed that both species would form in the post-shock gas after $\mathrm{CO}$ dissociates. For $\mathrm{CH}_{3} \mathrm{OH}, \mathrm{CH}_{4}+\mathrm{OH}$ or $\mathrm{CH}_{3}+\mathrm{H}_{2} \mathrm{O}$ could form $\mathrm{CH}_{3} \mathrm{OH}$ in the postshock gas (Latter \& Charnley 1996; Hartquist et al. 1995). $\mathrm{H}_{2} \mathrm{CO}$ would form in a similar manner with the reaction of $\mathrm{O}+\mathrm{CH}_{3}$ and then the release of a $\mathrm{H}$ atom (Cernicharo 2004). Another possible formation mechanism is $\mathrm{H}$ addition after the dissociation of $\mathrm{CO}$ in the post-shock gas.

Grain-surface reactions are also proposed to account for the abundance of oxygen bearing molecules. For example, Watanabe et al. (2004, and references therein) have shown that $\mathrm{H}_{2} \mathrm{CO}$ and $\mathrm{CH}_{3} \mathrm{OH}$ can form from both $\mathrm{CO}$ and $\mathrm{CO}-\mathrm{H}_{2} \mathrm{O}$ ice sprayed with cold $\mathrm{H}$. From this

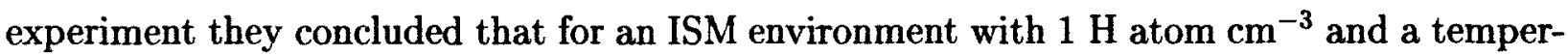
ature of $10 \mathrm{~K}$, a timescale of $10^{6}$ yr would be necessary to match observed $\mathrm{CO} / \mathrm{CH}_{3} \mathrm{OH}$ and $\mathrm{H}_{2} \mathrm{CO} / \mathrm{CH}_{3} \mathrm{OH}$ ratios in molecular clouds. Subsequent $\mathrm{H}$ addition has also been theorized to produce complex oxygen bearing organic molecules including propenal $\left(\mathrm{CH}_{2} \mathrm{CHCHO}\right)$ and propanal $\left(\mathrm{CH}_{3} \mathrm{CH}_{2} \mathrm{CHO}\right.$ ) (Hollis et al. 2004). To date, however, $\mathrm{CH}_{3} \mathrm{OH}$ has not been detected toward CRL 618 and the timescale of the PPN phase is only about ten thousand years. It is apparent that this formation mechanism would be too slow to produce detectable amounts of $\mathrm{CH}_{3} \mathrm{OH}$ in CRL 618.

Finally, there are also gas phase reaction schemes that attempt to predict the abundance of oxygen bearing organic molecules. In order to investigate whether gas phase reactions may be responsible for the formation of oxygen bearing organic molecules in the CSE of CRL 618 , we utilized the gas phase reactions of the UMIST database (Le Teuff et al. 1999) and 
compared the predicted fractional abundance to the upper limits measured from our survey. The limitation that we found to this procedure is the limited number of reactions to form the larger oxygen bearing organic molecules. However, we can discuss two molecular formation models and how they compare to our measured upper limits. Furthermore, as a constraint to our analysis, we only included formation models that contained molecules already detected toward CRL 618 or molecules that were structurally similar to other species but have not yet been detected.

We adopt a measured UV flux of $\sim 3 \times 10^{6}$ photons $\mathrm{s}^{-1}$, a $n_{\mathrm{H}_{2}}$ abundance of $10^{7} \mathrm{~cm}^{-3}$ and a temperature of $100 \mathrm{~K}$ (Herpin \& Cernicharo 2000). The proposed gas phase reaction formation of $\mathrm{HCOOH}$ is $\mathrm{HCO}^{+}+\mathrm{H}_{2} \mathrm{O} \rightarrow \mathrm{HCOOH}_{2}^{+}$and the destruction mechanism $\mathrm{HCOOH}$ $+\mathrm{h} \nu \rightarrow \mathrm{HCO}+\mathrm{OH}$. $\mathrm{HCO}^{+}$and $\mathrm{H}_{2} \mathrm{O}$ have been detected in the CSE of CRL 618 and their fractional abundances have also been measured. The calculated fractional abundance of $\mathrm{HCOOH}$ based on the formation model is $\sim 5 \times 10^{-11}$. The calculated upper limit based on our observations is $\mathrm{X}_{\mathrm{HCOOH} \sim 2 \times 10^{-9}}$. Thus, the combination of a lower abundance of $\mathrm{H}_{2} \mathrm{O}$ and $\mathrm{HCO}^{+}$and a higher $\mathrm{UV}$ ionization rate suggests that doubly-oxygenated molecules have abundances that are still too low to detect. No other oxygen bearing organic molecule we searched for had any formation mechanism based on species already found in the CSE of CRL 618 or formation models listed in the UMIST database.

However the situation is less clear for the singly oxygenated species such as $\mathrm{CH}_{3} \mathrm{CHO}$. The proposed gas phase reaction formation of $\mathrm{CH}_{3} \mathrm{CHO}$ is $\mathrm{O}+\mathrm{C}_{2} \mathrm{H}_{5} \rightarrow \mathrm{CH}_{3} \mathrm{CHO}+\mathrm{H}$ and the destruction mechanism $\mathrm{CH}_{3} \mathrm{CHO}+\mathrm{h} \nu \rightarrow \mathrm{CO}+\mathrm{CH}_{4} \cdot \mathrm{C}_{2} \mathrm{H}_{5}$ has not yet been detected in the CSE of CRL 618, however, $\mathrm{C}_{2} \mathrm{H}_{4}$ has been detected and the fractional abundance has been measured as $\sim 10^{-4}$. The calculated fractional abundance of $\mathrm{CH}_{3} \mathrm{CHO}$ based on the formation model is $\sim 5 \times 10^{-6}$. The calculated upper limit based on our observations is below this value, $\mathrm{X}_{\mathrm{CH}_{3} \mathrm{CHO} \sim 10^{-6}}$. The implication for the formation and detection of $\mathrm{CH}_{3} \mathrm{CHO}$ is that if the abundance of $\mathrm{C}_{2} \mathrm{H}_{5}$ is similar to $\mathrm{C}_{2} \mathrm{H}_{4}$ gas phase reactions like those listed above are not important to the formation of this molecule.

One obvious difference between PPNe and molecular cores that may account for the difference in grain surface reactions is their different grain properties. In the cold collapse phase of molecular cores, molecules are depleted onto ices, where hydrogenation then slowly changes the chemical composition of the mantles. The mantles are then evaporated during the hot core phase and the subsequent release of these mantle species into the gas phase can then drive the complex chemistry observed in hot molecular cores. The envelopes of AGB stars and PPNe on the other hand are the actual sites of the formation of carbon dust via the formation of PAHs. Hence grain properties are very different from star forming cores and the cold collapse phase is completely lacking. Therefore, if grain chemistry and the 
subsequent processing of the grain mantle products in a hot gas phase is the main route to produce large organic biomolecules in a large abundance, they cannot be expected to exist in PPNe. For further reviews of the chemistry leading to organic molecules see Tielens \& Charnley (1997) and Ehrenfreund \& Charnley (2000).

Indeed, while a complex chemisty is taking place toward PPNe, including CRL 618, it appears that the physical conditions and chemistry may not be efficient enough to produce and detect large organic biomolecules.

\section{Summary}

We have presented the results of our survey toward the protoplanetary nebula CRL 618 for several large, highly saturated, organic molecules of biological importance including acetaldehyde $\left(\mathrm{CH}_{3} \mathrm{CHO}\right)$, acetic acid $\left(\mathrm{CH}_{3} \mathrm{COOH}\right)$, dimethyl ether $\left(\mathrm{CH}_{3} \mathrm{OCH}_{3}\right)$, ethanol $\left(\mathrm{CH}_{3} \mathrm{CH}_{2} \mathrm{OH}\right)$, formic acid $(\mathrm{HCOOH})$ and methyl formate $\left(\mathrm{HCOOCH}_{3}\right)$; large carbon chain molecules including methyl cyanide $\left(\mathrm{CH}_{3} \mathrm{CN}\right)$, methylcyanoacetylene $\left(\mathrm{CH}_{3} \mathrm{C}_{3} \mathrm{~N}\right)$, cyanoacetylene $\left(\mathrm{HC}_{3} \mathrm{~N}\right)$, cyanodiacetylene $\left(\mathrm{HC}_{5} \mathrm{~N}\right)$ and $\mathrm{C}_{6} \mathrm{H}$; and finally smaller molecules including ${ }^{34} \mathrm{SO}, \mathrm{SO}_{2}, \mathrm{OC}^{34} \mathrm{~S}$ and $\mathrm{MgNC}$. No biologically important organic molecules were detected however, based on the $1 \sigma \mathrm{rms}$ noise level in the spectral windows containing our large molecular species, we were able to place upper limits on the column density and fractional adundances relative to $\mathrm{H}_{2}$ (Table 4). We made the first interferometric detection of $\mathrm{CH}_{3} \mathrm{CN}$ toward CRL 618. Using a rotational temperature diagram of the $J=6-5$ rotational transitions, we found a temperature of $88(44) \mathrm{K}$ and from the temperature and distribution of $\mathrm{CH}_{3} \mathrm{CN}$ toward $\mathrm{CRL} 618$, we find $\mathrm{CH}_{3} \mathrm{CN}$ is formed in the outer envelope surrounding the UC HII region. We also made the first interferometric detection of vibrationally excited $\mathrm{HC}_{5} \mathrm{~N}$ toward this source as well as detected transitions of the $\nu_{7}=3$ and 4 states of $\mathrm{HC}_{3} \mathrm{~N}$. The P-Cygni line profile and corresponding channel maps of vibrationally excited $\mathrm{HC}_{5} \mathrm{~N}$ supports its distribution in the extended circumstellar envelope expanding away from the central star. The detection of vibrationally excited $\mathrm{HC}_{3} \mathrm{~N}$ confirmed the temperature structure and column density of $\mathrm{HC}_{3} \mathrm{~N}$ in the extended envelope found by Wyrowski et al. (2003). Finally, our observations clearly indicate that CRL 618 is a good source of large carbon chain species but is a very poor source to detect or produce organic species of biological importance.

We acknowledge support from the Laboratory for Astronomical Imaging at the University of Illinois, and NSF AST 99-81363 and AST 02-28953. 


\section{REFERENCES}

Bauder, A., Lovas, F. J., \& Johnson, D. R. 1976, J. Phys. Chem. Ref. Data, 5, 53

Boucher, D., Burie, J., Bauer, A., Dubrulle, A., \& Demaison, J. 1980, J. Phys. Chem. Ref. Data, 9, 659

Bujarrabal, V., Bachiller, R., Alcolea, J., \& Martin-Pintado, J. 1988, A\&A, 206, L17

Cernicharo, J. 2004, ApJ, 608, L41

Cernicharo, J., Heras, A. M., Tielens, A. G. G. M., Pardo, J. R., Herpin, F., Guelin, M., \& Waters, L. B. F. M. 2001a, ApJ, 546, L123

Cernicharo, J., Heras, A. M., Pardo, J. R., Tielens, A. G. G. M., Guelin, M., Dartois, E., Neri, R., \& Waters, L. B. F. M. 2001b, ApJ, 546, L127

Cernicharo, J., Guelin, M., Martin-Pintado, J., Penalver, J., Mauersberger, R. 1989, A\&A, $222, \mathrm{~L} 1$

Cummins, S. E., Green, S., Thaddeus, P., \& Linke, R. A. 1983, ApJ, 266, 331

Ehrenfreund, P. \& Charnley, S. B. 2000, ARA\&A, 38, 427

Ehrenfreund, P., Bernstein, M. P., Dworkin, J. P., Sandford, S. A., \& Allamandola, L. J. 2001, ApJ, 550, L95

Friedel, D. N., Snyder, L. E., Turner, B. E., \& Remijan, A. 2004, ApJ, 600, 234

Fukasaku, S., Hirahara, Y., Masuda, A., Kawaguchi, K., Ishikawa, S., Kaifu, N., \& Irvine, W. M. ApJ, 1994, 437, 410

Goldsmith, P. F., \& Langer, W. D. 1999, ApJ, 517, 209

Groner, P., Albert, S., Herbst, E., \& de Lucia, F. C. 1998, ApJ, 500, 1059

Guelin, M., \& Cernicharo, J. 1991, A\&A, 244, 21L

Hartquist, T. W., Menten, K. M., Lepp, S. \& Dalgarno, A. 1995, MNRAS, 272, 184

Hasegawa, T. I., Herbst, E., \& Leung, C. M. 1992, ApJS, 82, 167

Herpin, F., \& Cernicharo, J. 2000, ApJ, 530, L129

Herpin, F., Goicoechea, J. R., Pardo, J. R., \& Cernicharo, J. 2002, ApJ, 577, 961 
Highberger, J. L., \& Ziurys, L. M. 2003, ApJ, 597, 1065

Hollenbach, D., \& Salpeter, E. E. 1971, ApJ, 163, 155

Hollis, J. M., Jewell, P. R., Lovas, F. J., Remijan, A., \& Møllendal, H. 2004, ApJ, 610, L21

Ilyushin, V. V., et al. 2001, J. Mol. Spectroscopy, 205, 286

Jennings, D. E., \& Fox, K. 1982, ApJ, 254, 111

Latter, W. B., \& Charnley, S. B. 1996, ApJ, 463, L37

Le Teuff, Y. H., Millar, T. J., \& Markwick, A. J. 1999, A\&AS, 146, 157

Liu, S.-Y., Girart, J. M., Remijan, A., \& Snyder, L. E. 2002, ApJ, 576, 255

Lovas, F. J. 1982, J. Phys. Chem. Ref. Data, 11, 251

Maki, A. G. 1974, J. Phys. Chem. Ref. Data, 3, 221

Mehringer, D. M., \& Snyder, L. E. 1996, ApJ, 471, 897

Müller, H. S. P., Thorwirth, S., Roth, D. A., \& Winnewisser, G. 2001, A\&A, 370, L49

Oesterling, L. C., Albert, S., de Lucia, F. C., Sastry, K. V. L. N., \& Herbst, E. 1999, ApJ, 521,255

Pardo, J. R., Cernicharo, J., Goicoechea, J. R., \& Phillips, T. G. 2004, ApJ, 615, 495

Pickett, H. M., Poynter, R. L., Cohen, E. A., Delitsky, M. L., Pearson, J. C., \& Muller, H. S. P. 1998, J. Quant. Spectrosc. Radiat. Transfer, 60, 883

Remijan, A., Snyder, L. E., Liu, S.-Y., Mehringer, D. M., \& Kuan, Y.-J. 2002, ApJ, 576, 264

Remijan, A., Snyder, L. E., Friedel, D. N., Liu, S.-Y., \& Shah, R. Y. 2003, ApJ, 590, 314

Remijan, A., Shiao, Y.-S., Friedel, D. N., Meier, D. S., \& Snyder, L. E. 2004a, ApJ, 617, 324

Remijan, A., Sutton, E. C., Snyder, L. E., Friedel, D. N., Liu, S.-Y., \& Pei, C. C. 2004b, ApJ, 606, 917

Sault, R. J., Teuben, P. J., \& Wright, M. C. H. 1995, in ASP Conf. Ser. 77, Astronomical Data Analysis Software and Systems IV, ed. R. A. Shaw, H. E. Payne, \& J. J. E. Hayes (San Francisco: ASP), 433 
Sanchez Contreras, C., \& Sahai, R. 2004, ApJ, 602, 960

Snyder, L. E., Lovas, F. J., Mehringer, D. M., Miao, N. Y., Kuan, Y.-J., Hollis, J. M., \& Jewell, P. R. 2002, ApJ, 578, 245

Solomon, P. M., Jefferts, K. B., Penzias, A. A., \& Wilson, R. W. 1971, ApJ, 168, L107

Sutton, E. C., Blake, G. A., Genzel, R., Masson, C. R., \& Phillips, T. G. 1986, ApJ, 311, 921

Thorwirth, S. 2001, Ph.D. thesis, Univ. Köln

Tielens, A. G. G. M., \& Hagen, W. 1982, A\&A, 114, 245

Tielens, A. G. G. M. \& Charnley, S. B. 1997, Origins of Life and Evolution of the Biosphere, 27,23

Tiemann, E. J. 1974, J. Phys. Chem. Ref. Data, 3, 259

Trammell, S. R. 2000, in ASP Conf. Ser. 199, Asymmetrical Planetary Nebulae II: From Origins to Microstructures, ed. J. Kastner, N. Soker, \& S. Rappaport (San Francisco:ASP), 147

Ueta, T., Fong, D., \& Meixner, M. 2001, ApJ, 557, 117

Watanabe, N., Nagaoka, A., Shiraki, T., \& Kouchi, A. 2004, ApJ, 616, 638

Woods, P. M., Millar, T. J., Herbst, E., \& Zijlstra, A. A. 2003, A\&A, 402, 189

Willemot, E., Dangoisse, D., Monnanteuil, N., \& Bellet, J. 1980, J. Phys. Chem. Ref. Data, 9,59

Winnewisser, G. \& Walmsley, C. M. 1978, A\&A, 70, 37L

Wyrowski, F., Schilke, P., Thorwirth, S., Menten, K. M., \& Winnewisser, G. 2003, ApJ, 586, 344

Wyrowski, F., Schilke, P., \& Walmsley, C. M. 1999, A\&A, 341, 882

Yamada, K. M. T, \& Creswell, R. A. 1986, J. Mol. Spectr. 116, 384

Yamada, K. M. T., Degli Esposti, C., Botschwina, P., Förster, P., Bizzocchi, L., Thorwirth, S., \& Winnewisser, G. 2004, A\&A, 425, 767 
Fig. 1. - Spectra of the four transitions of vibrationally excited $\mathrm{HC}_{5} \mathrm{~N}$ located in the passbands of our survey. (a) First detection the $\mathrm{HC}_{5} \mathrm{~N} \mathrm{~J}=40-39,(0,0,0,1)^{1+}$ transition toward CRL 618 seen in absorption and emission. The emission peaks near a $v_{L S R}$ of $-24 \mathrm{~km} \mathrm{~s}^{-1}$. The spectral line label in the upper left of each panel is the rest frequency of each $\mathrm{HC}_{5} \mathrm{~N}$ transition for a $v_{L S R}$ of $-27.5 \mathrm{~km} \mathrm{~s}^{-1}$. The dashed line is centered on the $v_{L S R}$ of CRL 618 $\left(-27.5 \mathrm{~km} \mathrm{~s}^{-1}\right)$. Near $40 \mathrm{~km} \mathrm{~s}^{-1}$, we begin to detect the ${ }^{34} \mathrm{SO} 2(3)-1(2)$ transition in emission. We also label the location of the $\mathrm{C}_{6} \mathrm{H}^{2} \Pi_{3 / 2} \mathrm{~J}=77 / 2-75 / 2 \mathrm{f}$ transition. The $1 \sigma \mathrm{rms}$ noise level is $\sim 40 \mathrm{mJy}^{\text {beam }}{ }^{-1}$ (indicated by the vertical bar at the left of each spectrum). (b) Passband containing the $\mathrm{HC}_{5} \mathrm{~N} \mathrm{~J}=40-39,(0,0,0,3)^{1-}$ transition toward CRL 618. No spectral feature is detected beyond the $1 \sigma \mathrm{rms}$ noise level. (c) Passband containing the $\mathrm{HC}_{5} \mathrm{~N}$ $\mathrm{J}=40-39,(0,0,0,3)^{1+}$ transition toward CRL 618 . No spectral feature is detected beyond the $1 \sigma \mathrm{rms}$ noise level. (d) Passband containing the $\mathrm{HC}_{5} \mathrm{~N} \mathrm{~J}=40-39,(0,0,0,4)$ transition toward CRL 618. We also label the location of the $\operatorname{MgNC} N=9-8$ transition. No spectral feature is detected beyond the $1 \sigma \mathrm{rms}$ noise level, however the $\mathrm{MgNC}$ transition is beginning to be resolved out of the noise (\$4.4).

Fig. 2.- Spectra of the detected transitions of $\mathrm{CH}_{3} \mathrm{CN}$ and $\mathrm{HC}_{3} \mathrm{~N}$ found from our survey toward CRL 618. (a) First detection of the $J=6-5$ rotational transitions of $\mathrm{CH}_{3} \mathrm{CN}$ seen entirely in emission. Between the $K=2$ and $K=3$ lines of $\mathrm{CH}_{3} \mathrm{CN}$ lies the $J=12-11$ $(0,1,0,3)^{1+}$ vibrational transition of $\mathrm{HC}_{3} \mathrm{~N}$ seen in absorption. The measured $v_{L S R}$ of the absorption trough of $\mathrm{HC}_{3} \mathrm{~N}$ is $-27.5 \mathrm{~km} \mathrm{~s}^{-1}$. The spectral line label in the upper left of the panel is the rest frequency of the $\mathrm{HC}_{3} \mathrm{~N}$ transition. The $1 \sigma \mathrm{rms}$ noise level is $\sim 40 \mathrm{mJy}$ beam $^{-1}$ (indicated by the vertical bar at the left of each spectrum). (b) Spectrum of 3 vibrationally excited transitions of $\mathrm{HC}_{3} \mathrm{~N}$. Each of these transitions lie at a $v_{L S R}$ of $-27.5 \mathrm{~km}$ $\mathrm{s}^{-1}$. The spectral line labels located in the upper left of the panel corresponds to the rest frequency of the $\mathrm{HC}_{3} \mathrm{~N} J=12-11(0,0,0,4)^{0}$ transition.

Fig. 3.- $-\mathrm{HC}_{5} \mathrm{~N}$ velocity-channel maps toward $\mathrm{CRL} 618$. The data displayed are a combination of the $\mathrm{B}$ and $\mathrm{C}$ array data. The LSR velocities of the absorption and emission features are indicated in $\mathrm{km} \mathrm{s}^{-1}$ units at the top right of each panel. The contour level ranges are $-0.24,-0.20,-0.16,-0.12,-0.08,0.08,0.12,0.16,0.20,0.24$ and $0.28 \mathrm{Jy} \mathrm{beam}^{-1}$. The synthesized beam of $5 . " 8 \times 5 . " 1$ is shown at the lower left of each panel. The last panel shows the $3 \mathrm{~mm}$ continuum emission toward CRL 618 in the BIMA B array The synthesized beam of $3 . " 0 \times 1 . " 9$ is shown at the lower left of this panel. The continuum emission peak at an intensity of $1.86 \mathrm{Jy}^{\text {beam }}{ }^{-1}$ at a frequency near $108 \mathrm{GHz}$.

Fig. 4. $-\mathrm{HC}_{3} \mathrm{~N} v_{7}=4$ velocity-channel maps toward CRL 618. The data displayed are a 
combination of the $\mathrm{B}$ and $\mathrm{C}$ array data. The panel labels and beamsizes are the same as in Figure (2). The contour level ranges are $-0.36,-0.32,-0.28,-0.24,-0.20,-0.16,-0.12,-0.08$, 0.08 , and $0.12 \mathrm{Jy} \mathrm{beam}^{-1}$.

Fig. 5.- Rotational temperature diagram for the observed $\mathrm{CH}_{3} \mathrm{CN}$ transitions toward $\mathrm{CRL}$ 618. Ordinate: $\ln \left(N_{u} / g_{u}\right)$. Abscissa: $E_{u}(\mathrm{~K})$. The least- squares fit is shown as a solid line. The resulting rotational temperature is $88(44) \mathrm{K}$ in a beam size of $5 . " 8 \times 5 . " 1$. 


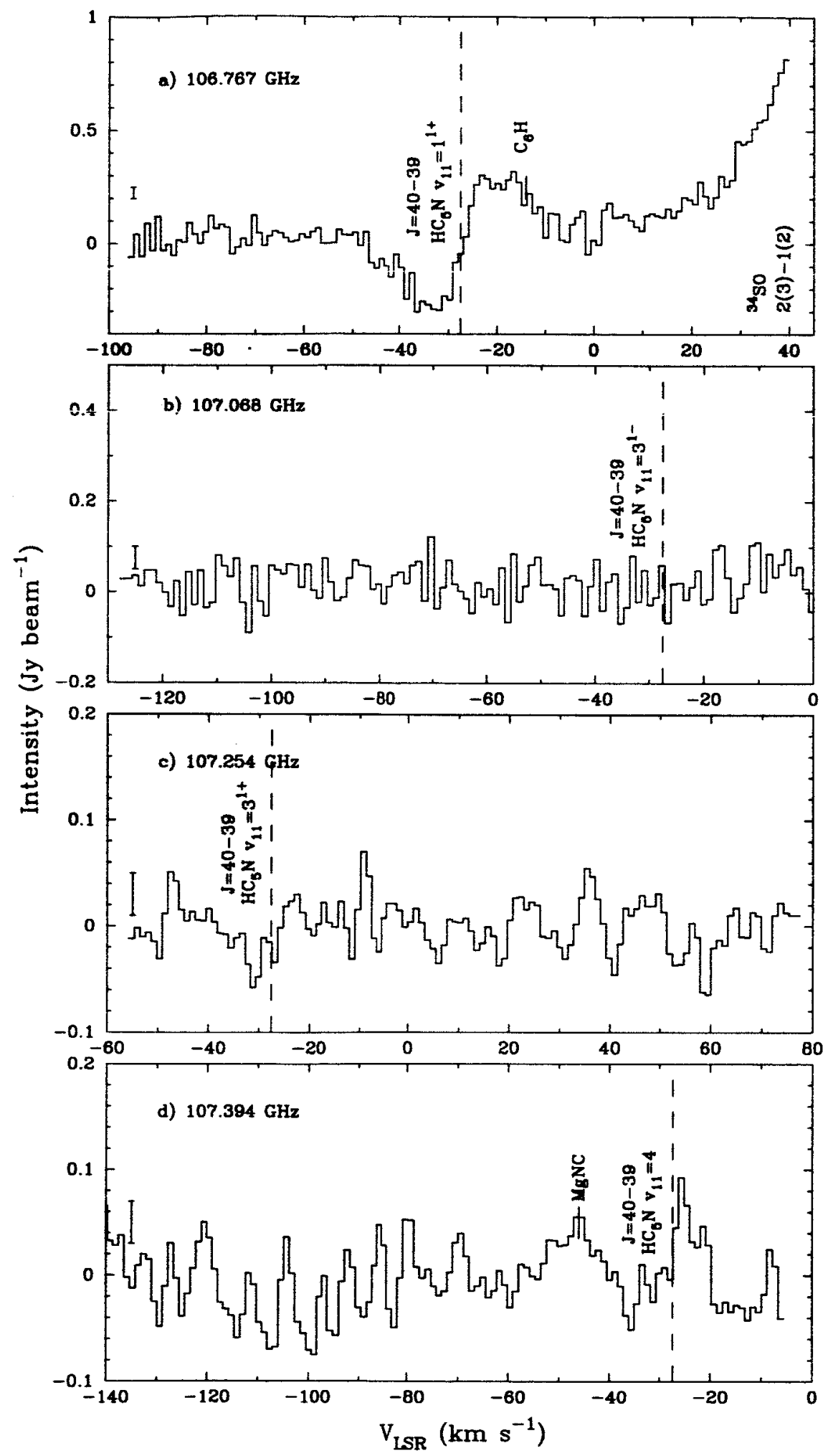

Figure 1. 


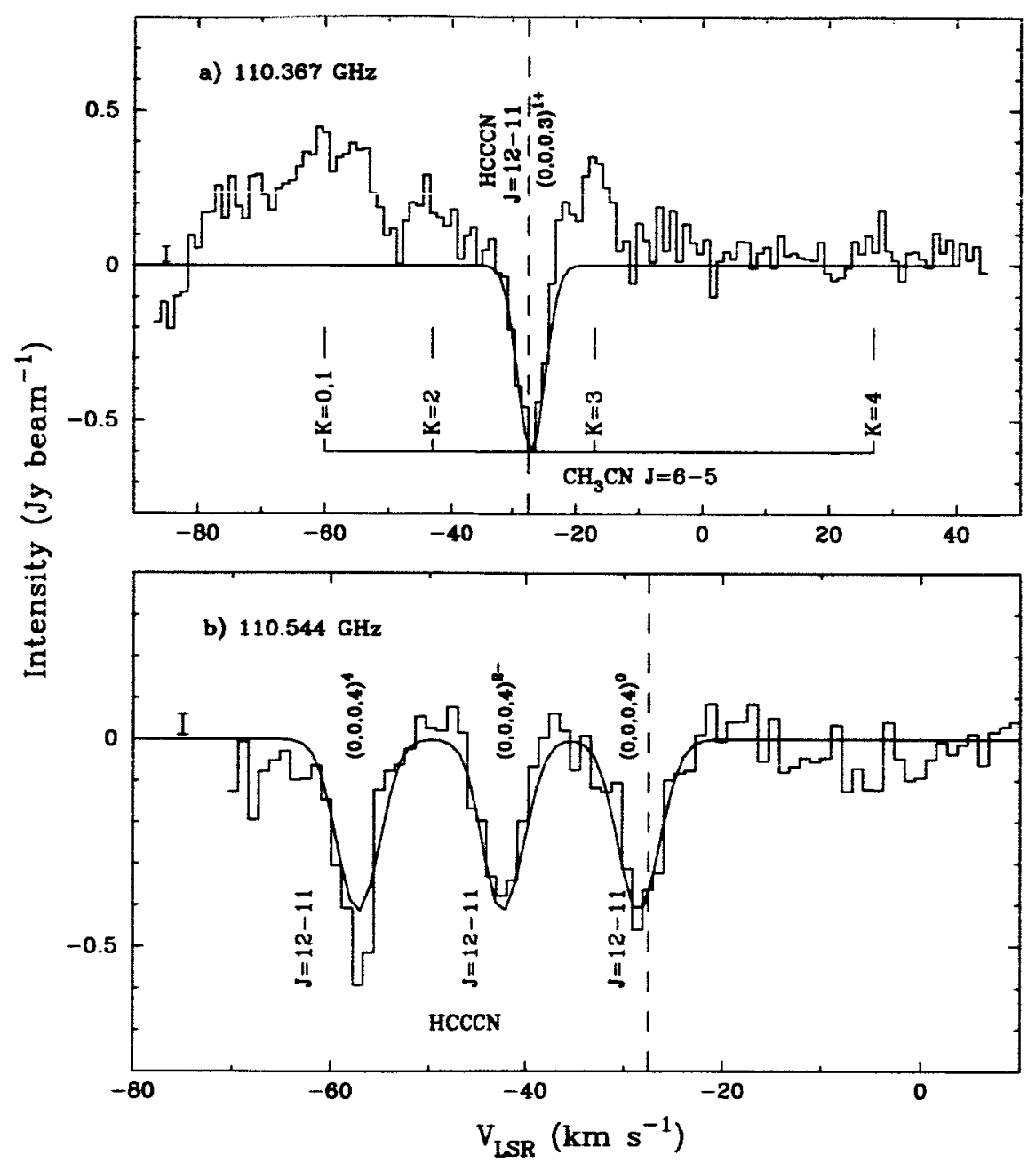

Figure 2. 


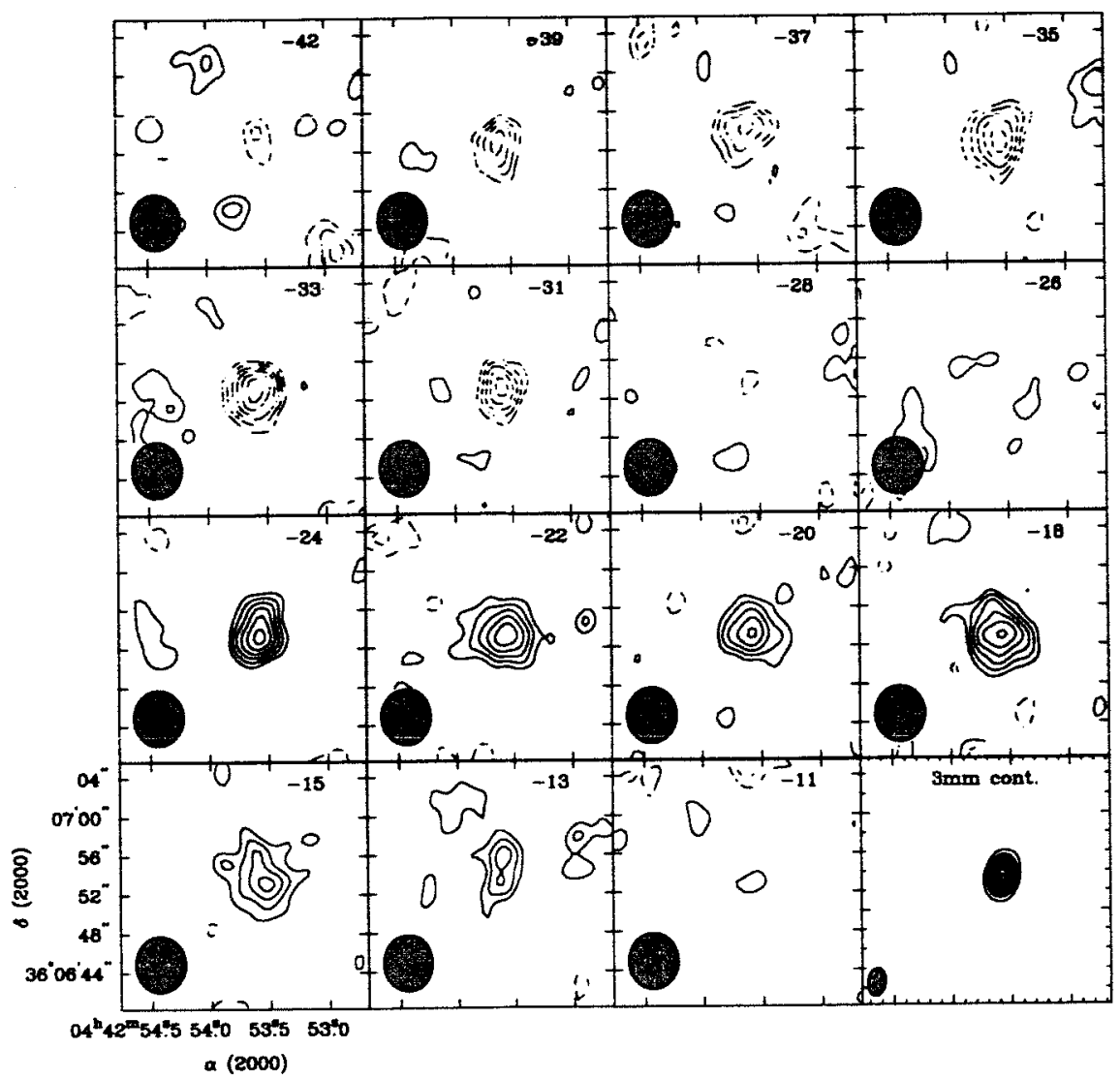

Figure 3. 


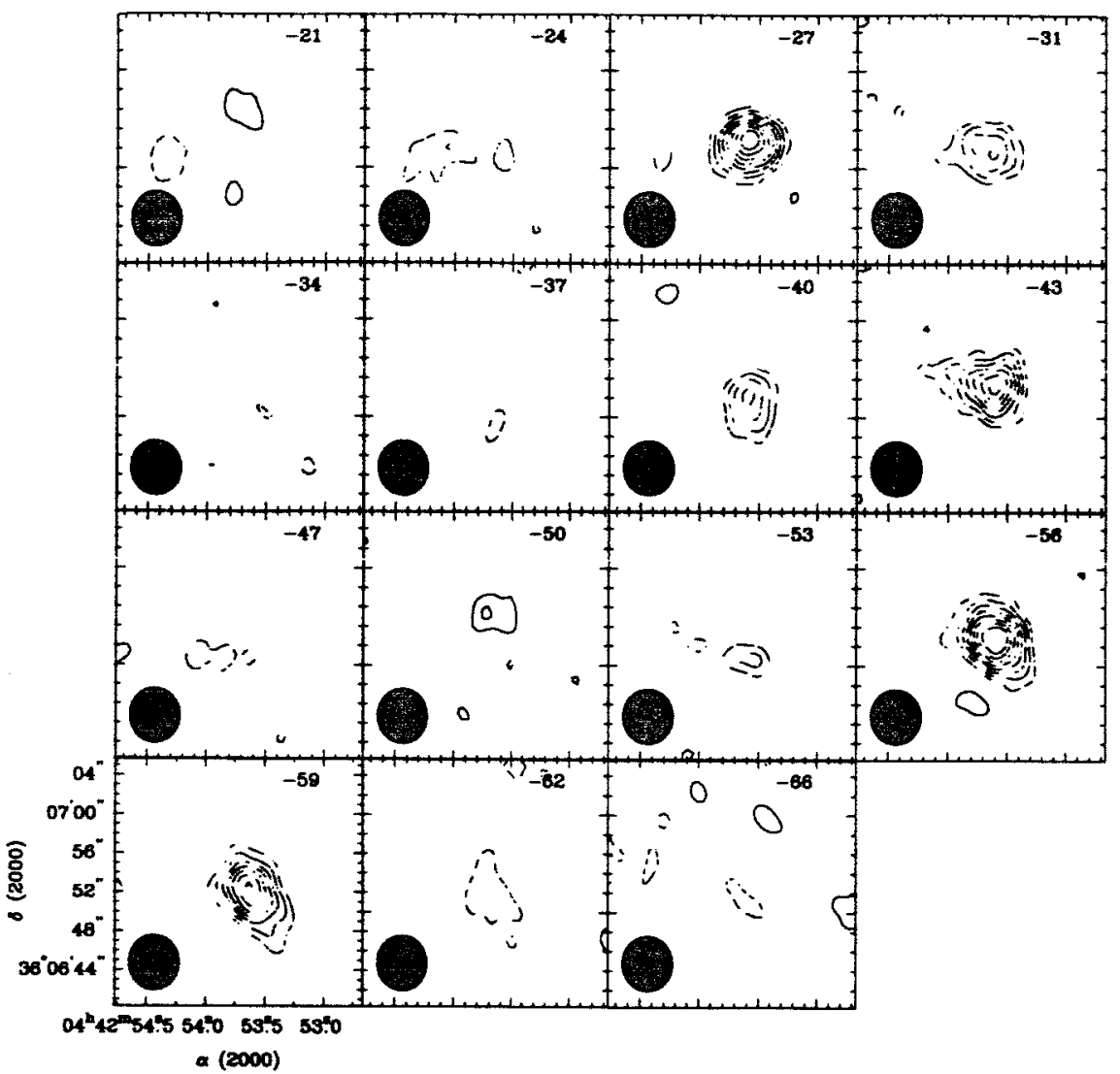

Figure 4

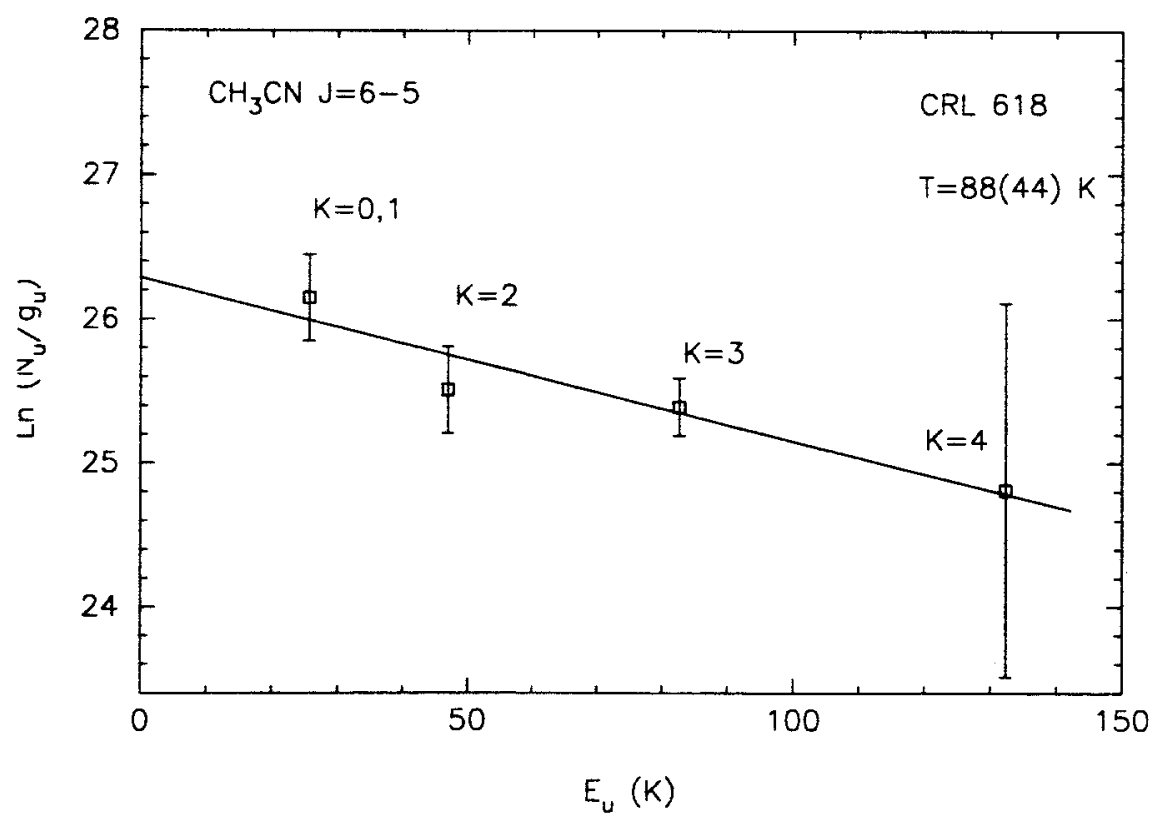

Figure 5. 
Table 1. Observational Parameters

\begin{tabular}{|c|c|c|c|c|c|}
\hline $\begin{array}{l}\text { Observation Date } \\
\text { (1) }\end{array}$ & $\begin{array}{c}\text { Gain Calibrator } \\
\text { (2) }\end{array}$ & $\begin{array}{l}\text { Flux Calibrator } \\
\text { (3) }\end{array}$ & $\begin{array}{l}\text { Frequency } \\
\text { (GHz) } \\
(4)\end{array}$ & $\begin{array}{l}\text { Array } \\
\text { (5) }\end{array}$ & $\begin{array}{c}\text { Beam } \\
(\operatorname{arcsec} \times \operatorname{arcsec}) \\
(6)\end{array}$ \\
\hline 2002 Oct 11 & $0359+509$ & Saturn & 111.5 & C & $7.18 \times 6.59$ \\
\hline 2002 Oct 19 & $0359+509$ & Saturn & 111.5 & C & $6.97 \times 6.50$ \\
\hline 2002 Nov 04 & $0359+509$ & Jupiter & 110.3 & $\mathbf{C}$ & $6.91 \times 6.43$ \\
\hline 2002 Nov 18 & $0359+509$ & Saturn & 111.5 & C & $7.46 \times 6.66$ \\
\hline $2003 \operatorname{Jan} 28$ & $0359+509$ & Jupiter & 110.3 & $\mathbf{B}$ & $2.90 \times 1.84$ \\
\hline $2003 \operatorname{Jan} 31$ & $0359+509$ & Jupiter & 111.5 & $\mathbf{B}$ & $3.72 \times 1.90$ \\
\hline 2003 Feb 01 & $0359+509$ & Jupiter & 111.5 & B & $2.75 \times 1.96$ \\
\hline 2003 Feb 03 & $0359+509$ & Iupiter & 111.5 & $\mathrm{~B}$ & $3.48 \times 2.04$ \\
\hline
\end{tabular}

Table 2. Molecular Line Parameters

\begin{tabular}{|c|c|c|c|c|c|}
\hline Species & Transition & $\begin{array}{c}\text { Frequency } \\
(\mathrm{MHz})\end{array}$ & $\begin{array}{c}\left\langle S_{i, j} \mu^{2}>\right. \\
\left(\text { Debye }^{2}\right)\end{array}$ & $\begin{array}{l}E_{u} \\
(K)\end{array}$ & Qr \\
\hline $\mathrm{C}_{6} \mathrm{H}^{\mathrm{b}}$ & ${ }^{2} \Pi_{3 / 2} \mathrm{~J}=77 / 2-75 / 2 \mathrm{f}$ & $106,762.470(90)$ & 1340.2 & 101.2 & $89.8 \mathrm{~T}$ \\
\hline${ }^{3_{4}} \mathrm{SO}^{\mathrm{c}}$ & $2(3)-1(2)$ & $106,743.374(18)$ & 3.6 & 21.0 & $2.9 \mathrm{~T}$ \\
\hline$O C^{34} S^{d}$ & $9-8$ & $106,787.380(80)$ & 4.6 & 25.7 & 3.4T \\
\hline $\mathrm{SO}_{2}{ }^{\mathrm{b}}$ & $273,25-264,22$ & $107,060.209(3)$ & 8.3 & 370.5 & $1.1 \mathrm{~T}^{3 / 2}$ \\
\hline $\mathrm{MgNC}^{\mathrm{b}}$ & $9-8$ & $107,399.800(400)$ & 245.2 & 25.9 & $7.0 \mathrm{~T}$ \\
\hline \multirow[t]{5}{*}{$\mathrm{CH}_{3} \mathrm{CN}^{\circ}$} & $6(4)-5(4)$ & $110,349.760(200)$ & 51.0 & 132.3 & $1.0 \mathrm{~T}^{3 / 2}$ \\
\hline & $6(3)-5(3)$ & $110,364.470(100)$ & 68.9 & 82.6 & \\
\hline & $6(2)-5(2)$ & $110,374.986(120)$ & 81.6 & 47.0 & \\
\hline & $6(1)-5(1)$ & $110,381.376(120)$ & 89.3 & 25.7 & \\
\hline & $6(0)-5(0)$ & $110,383.494(120)$ & 91.9 & 18.6 & \\
\hline \multirow[t]{4}{*}{$\left(\mathrm{CH}_{3}\right)_{2} \mathrm{O}^{\mathrm{f}}$} & $9_{1,8-8_{2,7} \mathrm{AA}}$ & $106,775.679(80)$ & 3.66 & 43.4 & $91.6 \mathrm{~T}^{3 / 2}$ \\
\hline & $9_{1,8}-8_{2,7} \mathrm{EE}$ & $106,777.371(80)$ & 3.66 & 43.4 & \\
\hline & $9_{1,8}-8_{2,7} A E$ & $106,779.058(80)$ & 3.66 & 43.4 & \\
\hline & $9_{1,8}-8,7 \mathrm{EA}$ & $106,779.066(80)$ & 3.66 & 43.4 & \\
\hline $\mathrm{CH}_{3} \mathrm{CHO}^{\mathrm{b}, \mathrm{g}}$ & $3_{1,2}-2_{0,2} E$ & $107,887.477(1598)$ & 0.02 & 8.07 & $2.3 T^{3 / 2}$ \\
\hline \multirow[t]{2}{*}{$\mathrm{CH}_{3} \mathrm{COOH}^{\mathrm{b}}$} & $10 *, 10-9 *, 9 \mathrm{E}$ & $111,507.270(40)$ & 54.8 & 30.5 & $14.1 \mathrm{~T}^{3 / 2}$ \\
\hline & $10 *, 10-9 ., 9 \mathrm{~A}$ & $111,548.533(40)$ & 54.8 & 30.5 & \\
\hline \multirow[t]{4}{*}{$\mathrm{CH}_{3} \mathrm{C}_{3} \mathrm{~N}^{\mathrm{i}}$} & $27(6)-26(6)$ & $111,503.905(3)$ & 579.1 & 345.3 & 8. $T T^{3 / 2}$ \\
\hline & $27(5)-26(5)$ & $111,515.692(3)$ & 588.3 & 262.8 & \\
\hline & $27(1)-26(1)$ & $111,541.424(4)$ & 608.4 & 82.7 & \\
\hline & $27(0)-26(0)$ & $111,542.497(4)$ & 609.2 & 75.2 & \\
\hline \multirow[t]{3}{*}{$\mathrm{CH}_{3} \mathrm{CH}_{2} \mathrm{OH}^{\mathrm{j}}$} & $12_{7,6}-13_{6,7}$ & $111,510.340(31)$ & 1.7 & 127.4 & $6.5 \mathrm{~T}^{3 / 2}$ \\
\hline & $127,5-13,6,8$ & $111,510.550(31)$ & 1.7 & 127.4 & \\
\hline & $8_{2,7}-8_{0,8}$ & $111,738.020(19)$ & 0.1 & 35.3 & \\
\hline HCOOHk & $5,0,5-40,4$ & $111,746.780(10)$ & 10.0 & 16.2 & $1.7 \mathrm{~T}^{3 / 2}$ \\
\hline \multirow{5}{*}{$\mathrm{HCOOCH}_{3}{ }^{1}$} & $9_{7,2}-87,1 \mathrm{E}$ & $110,525.598(32)$ & 59.2 & 9.6 & $12.4 \mathrm{~T}^{3 / 2}$ \\
\hline & $97,3-87,2$ A & $110,535.182(28)$ & 59.2 & 9.6 & \\
\hline & $9_{7,2}-8_{7,1} \mathrm{~A}$ & $110,535.184(28)$ & 59.2 & 9.6 & \\
\hline & $97,3-87,2 \mathrm{E}$ & $110,535.955(26)$ & 59.2 & 9.6 & \\
\hline & $7_{2,6}-6_{1,5} \mathrm{E}$ & $110,550.217(28)$ & 19.0 & 1.4 & \\
\hline
\end{tabular}


Table 2-Continued

\begin{tabular}{|c|c|c|c|c|c|}
\hline Species & Transition & $\begin{array}{c}\text { Frequency } \\
(\mathrm{MHz})\end{array}$ & $\begin{array}{c}<S_{i, j} \mu^{2}> \\
\left(\text { Debye }^{2}\right)\end{array}$ & $\begin{array}{l}\mathbf{E}_{\boldsymbol{u}} \\
(\mathrm{K})\end{array}$ & $\mathbf{Q}_{\boldsymbol{r}}$ \\
\hline & $72,6-61,5 A$ & $110,560.053(30)$ & 19.0 & 1.4 & \\
\hline & $9_{1,8-8_{1,7}} \mathrm{E}$ & $111,674.070(13)$ & 22.8 & 28.9 & \\
\hline & $\mathbf{S}_{1,8}-\mathbf{8}_{1,7} A$ & $111,682.224(13)$ & 22.8 & 28.9 & \\
\hline & $10_{1,10}-9_{0,9} \mathrm{E}$ & $111,733.936(14)$ & 3.8 & 30.3 & \\
\hline & $10_{1,10}-9_{0,9} A$ & $111,735.329(15)$ & 3.8 & 30.3 & \\
\hline \multirow[t]{4}{*}{$\mathrm{HC}_{3} \mathrm{~N}^{\mathrm{m}}$} & $\mathrm{J}=12-11(0,0,0,4)^{0}$ & $110,543.700(130)$ & 169.4 & 1314.4 & 13.TT \\
\hline & $\mathrm{J}=12-11(0,0,0,4)^{2-}$ & $110,549.013(1594)$ & 169.3 & 1314.4 & \\
\hline & $J=12-11(0,0,0,4)^{4}$ & $110,554.377(42)$ & 169.3 & 1314.4 & \\
\hline & $\mathrm{J}=12-11(0,1,0,3)^{1+}$ & $110,366.474(337)$ & 169.0 & 994.4 & \\
\hline \multirow[t]{5}{*}{$\mathrm{HC}_{5} \mathrm{~N}^{\mathrm{n}}$} & $J=40-39(0,0,0,1)^{1+}$ & $106,767.4842(44)$ & 749.96 & 259.4 & $15.7 \mathrm{~T}$ \\
\hline & $J=40-39(0,0,0,3)^{1-}$ & $107,068.1920(300)$ & 750.0 & 568.2 & \\
\hline & $\mathrm{J}=40-39(0,0,0,3)^{1+}$ & $107,254.3370(300)$ & 750.0 & 568.4 & \\
\hline & $\mathrm{J}=40-39(0,0,0,4)^{4-}$ & $107,394.3161(50)$ & 750.0 & 726.2 & \\
\hline & $J=40-39(0,0,0,4)^{4 t}$ & $107,394.3435(50)$ & 750.0 & 726.2 & \\
\hline
\end{tabular}

2Errors are $2 \sigma$

bPickett et al. (1998)

cTiemann (1974)

dMaki (1974)

eBoucher (1980)

${ }^{f}$ Groner et al. (1998)

gBauder (1976)

${ }^{\text {h}}$ Illuyshin et al. (2001)

${ }^{i}$ Mūller et al. (2001)

jLovas (1982)

${ }^{k}$ Willemot et al. (1980)

${ }^{1}$ Oesterling et al. (1999)

${ }^{m}$ Wyrowski et al. (1999), Yamada \& Creswell (1986)

"Yamada et al. (2004), Müller et al. (2001) 
Table 3. Line Detections

\begin{tabular}{ccccc}
\hline \hline $\begin{array}{c}\text { Frequency } \\
(\mathrm{MHz})\end{array}$ & Species & Transition & $\begin{array}{c}v_{L S R} \\
\left(\mathrm{~km} \mathrm{~s}^{-1}\right)\end{array}$ & $\begin{array}{c}\int \Delta I d v \\
\left(\mathrm{Jy}_{\text {beam }}{ }^{-1} \mathbf{k m ~ s}^{-1}\right)\end{array}$ \\
\hline $106,767.4842(44)$ & $\mathrm{HC}_{5} \mathrm{~N}$ & $\mathrm{~J}=40-39(0,0,0,1)^{1+}$ & -24 & $4.74(1.9)$ \\
& & & -34 & $-4.15(1.7)$ \\
$106,743.374$ & ${ }^{34} \mathrm{SO}$ & $2(3)-1(2)$ & & $\ldots{ }^{\mathrm{a}}$ \\
$110,349.760(200)$ & $\mathrm{CH}_{3} \mathrm{CN}$ & $6(4)-5(4)$ & -27.5 & $0.58(42)$ \\
$110,364.470(100)$ & $\mathrm{CH}_{3} \mathrm{CN}$ & $6(3)-5(3)$ & -27.5 & $2.77(18)$ \\
$110,366.742(337)$ & $\mathrm{HC}_{3} \mathrm{~N}$ & $12-11(0,1,0,3)^{1+}$ & -27.5 & $-2.69(30)$ \\
$110,374.986(120)$ & $\mathrm{CH}_{3} \mathrm{CN}$ & $6(2)-5(2)$ & -27.5 & $1.85(17)$ \\
$110,381.376(120)$ & $\mathrm{CH}_{3} \mathrm{CN}$ & $6(1)-5(1)$ & & $\ldots$ \\
$110,383.494(120)$ & $\mathrm{CH}_{3} \mathrm{CN}$ & $6(0)-5(0)$ & -27.5 & $7.63(24)^{\mathrm{b}}$ \\
$110,543.508(130)$ & $\mathrm{HC}_{3} \mathrm{~N}$ & $12-11(0,0,0,4)^{0}$ & -27.5 & $-1.56(3)$ \\
$110,550.328(1594)$ & $\mathrm{HC}_{3} \mathrm{~N}$ & $12-11(0,0,0,4)^{2-}$ & -27.5 & $-1.38(3)$ \\
$110,554.742(42)$ & $\mathrm{HC}_{3} \mathrm{~N}$ & $12-11(0,0,0,4)^{4}$ & -27.5 & $1.92(3)^{\mathrm{c}}$ \\
\hline
\end{tabular}

a Because we did not see the line peak, no attempt was made to fit this transition.

${ }^{b}$ Because the $K=0 \& 1$ components could not be fit with separate Gaussians, a one Gaussian fit was applied to both lines.

${ }^{c}$ This line may be blended with the $15_{4,2}-14_{5,2}$ transition of $\mathrm{c}_{-} \mathrm{C}_{3} \mathrm{H}_{2}$ at 110.558 (9) $\mathrm{GHz}$ (Pickett et al. 1998). 
Table 4. Column Densities

\begin{tabular}{|c|c|c|c|}
\hline Species & $\begin{array}{l}\text { Frequency } \\
(\mathrm{MHz})\end{array}$ & $\begin{array}{c}N_{\text {Tot }} \\
\left(\mathrm{cm}^{-2}\right)\end{array}$ & $\mathrm{X}\left(\mathrm{H}_{2}\right)$ \\
\hline \multicolumn{4}{|c|}{ Detections } \\
\hline $\begin{array}{c}\mathrm{HC}_{5} \mathrm{~N}^{\mathrm{a}} \\
\mathrm{HC}_{3} \mathrm{~N} \\
\mathrm{CH}_{3} \mathrm{CN}\end{array}$ & $\begin{array}{c}106,767.484 \\
\ldots b \\
\ldots b\end{array}$ & $\begin{array}{c}9.9 \times 10^{14} \\
4.7(6) \times 10^{17} \\
3.2(3) \times 10^{14}\end{array}$ & $\begin{array}{c}7.6 \times 10^{-9} \\
3.6(5) \times 10^{-6} \\
2.4(3) \times 10^{-9}\end{array}$ \\
\hline \multicolumn{4}{|c|}{ Upper Limits } \\
\hline $\mathrm{C}_{6} \mathrm{H}$ & $106,762.470$ & $2.5 \times 10^{13}$ & $1.9 \times 10^{-10}$ \\
\hline$O C^{34} \mathrm{~S}$ & $106,787.380$ & $1.2 \times 10^{14}$ & $9.1 \times 10^{-10}$ \\
\hline $\mathrm{SO}_{2}$ & $107,060.209$ & $1.0 \times 10^{16}$ & $7.8 \times 10^{-8}$ \\
\hline $\mathrm{MgNC}$ & $107,399.800$ & $4.4 \times 10^{12}$ & $3.4 \times 10^{-11}$ \\
\hline $\mathrm{HCOOCH}_{3}$ & $110,550.217$ & $1.1 \times 10^{16}$ & $8.5 \times 10^{-8}$ \\
\hline$\left(\mathrm{CH}_{3}\right)_{2} \mathrm{O}$ & $106,777.371$ & $1.0 \times 10^{17}$ & $7.9 \times 10^{-7}$ \\
\hline $\mathrm{CH}_{3} \mathrm{CHO}$ & $107,887.477$ & $1.4 \times 10^{17}$ & $1.1 \times 10^{-6}$ \\
\hline $\mathrm{CH}_{3} \mathrm{COOH}$ & $111,548.533$ & $3.5 \times 10^{14}$ & $2.7 \times 10^{-9}$ \\
\hline $\mathrm{CH}_{3} \mathrm{C}_{3} \mathrm{~N}$ & $111,542.497$ & $3.3 \times 10^{13}$ & $2.5 \times 10^{-10}$ \\
\hline $\mathrm{CH}_{3} \mathrm{CH}_{2} \mathrm{OH}$ & $111,738.020$ & $9.4 \times 10^{16}$ & $7.3 \times 10^{-7}$ \\
\hline $\mathrm{HCOOH}$ & $111,746.780$ & $2.0 \times 10^{14}$ & $1.5 \times 10^{-9}$ \\
\hline
\end{tabular}

